\title{
Corridor One: An Integrated Distance Visualization Environment for SSI and ASCI Applications
}

Final Report

Rick Stevens

Argonne National Laboratory

Table of Contents

A. Introduction

A.1. Corridors at a Distance Purpose

B. Scenarios

B.1. What is a Scenario?

B.2. Distributed Decision Making Scenario

$\begin{array}{ll}\text { B.2.a. Requirements } & 2\end{array}$

\begin{tabular}{ll} 
B.2.b. Assumptions & 2 \\
\hline $.2 . c$. & Scenario
\end{tabular}

$\begin{array}{ll}\text { B.2.c. Scenario } & 3\end{array}$

B.2.d. Technology Requirements 4

B.3. Remote Interactive Computing Scenario 5

$\begin{array}{lll}\text { B.3.a. Requirements } & 5\end{array}$

$\begin{array}{ll}\text { B.3.b. Assumptions } & 5\end{array}$

B.3.c. Scenario: Computational Flow Around a Projectile/Airfoil/Heart Valve 6

B.4. Remote Visualization Scenarios $\quad 7$

$\begin{array}{lll}\text { B.4.a. Requirements } & 7\end{array}$

$\begin{array}{ll}\text { B.4.b. Assumptions } & 7\end{array}$

B.4.c. Scenario: Remote Immersive Visualization $\quad 7$

B.4.d. Scenario: Remote Scientific Visualization $\quad 7$

B.4.e. Technology Requirements $\quad 8$

B.5. Remote Virtual Prototyping and Design Scenario $\quad 8$

$\begin{array}{lll}\text { B.5.a. Scenario } & 8\end{array}$

B.5.b. Technology Requirements 9

C. Road Maps 11

C.1. What is a Road Map?

C.2. Networking and QoS Road Map 11

C.2.a. DVC Possible WAN Interconnection Points 11

C.2.b. Networking Technology Road Map $\quad 12$

C.2.c. Bandwidth Requirements 14

C.2.d. Tele-Immersion Networking Requirements 14

$\begin{array}{ll}\text { C.2.e. Networking Requirements } & 15\end{array}$

$\begin{array}{lll}\text { C.2.f. } & \text { SuperCorridor Road Map } & 16\end{array}$

C.2.g. $\quad$ Networking Technology Road Map Rationale 19

C.2.h. Networking Requirements of Future High-End Scientific Simulation Applications 20

C.3. Remote Computing Road Map 25

C.3.a. Remote Computing Functionality and Technology Road Maps 25

C.3.b. $\quad$ Remote Computing Road Map Rationale 26

C.4. Remote Visualization Road Map 27

C.4.a. Remote Visualization Functionality and Technology Road Maps 27

C.4.b. Remote Visualization Road Map Rationale $\quad 29$

C.5. Remote Data Road Map

$\begin{array}{lll}\text { C.5.a. } & \text { Remote Data Functionality and Technology Road Maps } & 31\end{array}$

C.5.b. Remote Data Road Map Rationale 


\section{A. Introduction}

\section{A.1. Corridors at a Distance Purpose}

As computers enter the tera-op regime and experiments routinely return terabytes of data, our ability to see and understand scientific data is falling far short of our ability to create it. To address this issue, the Department of Energy (DOE) and the National Science Foundation (NSF) co-sponsored a series of workshops on the pacing problem of gleaning understanding from massive scientific datasets. A report on these workshops, Data and Visualization Corridors, Report on the 1998 Data and Visualization Corridor (DVC) Workshop Series, Technical Report CACR-164, published in November 1998 by California Institute of Technology, described hardware/software infrastructures. ${ }^{1}$

\section{B. Scenarios}

\section{B.1. What is a Scenario?}

Scenarios describe realistic uses of DVC/Distance technologies in several years. Four scenarios are described:

- Distributed Decision Making

- Remote Interactive Computing

- Remote Visualization: (a) Remote Immersive Visualization and (b) Remote Scientific Visualization

- Remote Virtual Prototyping

Scenarios serve as drivers for the road maps and enable us to check that the functionality and technology in the road maps match application needs.

\section{B.2. Distributed Decision Making Scenario}

\section{B.2.a. Requirements}

- Groups at several geographically distributed sites are involved in a group decision.

- Each group has a high-resolution "PowerWall" that can function as a shared "white board."

- Windows on this white board can support stereo video, views of remote participants, etc.

- All participants have "wands" or "laser pointers" that display simultaneously at all sites.

- Each "window" is controlled from its own site; some (e.g., spreadsheets) might have distributed control.

\section{B.2.b. Assumptions}

- The big picture

- Issues

- What is the likely yield?

- Should we perform conventional surgical strike?

- Should we perform a ground invasion?

- Should we perform a nuclear first strike?

- Each alternative requires decision makers to gather and analyze existing and new data within a time window

- Decision makers are not going to change their baseline processes because of new technologies.

- Multiple decision makers-Distributed sites are involved

- Washington (White House, Pentagon)

- DOE Defense Programs Labs (weapon analysis)

- DOD Engineering Labs (structures/weather)

- DOD Command Centers (planning/logistics)

- Scenario characteristics

- Geographically distributed sites

\footnotetext{
1 This report addresses critical computational, data management, and visualization requirements of urgent federal missions. In particular, the Accelerated Strategic Computing Initiative (ASCI) is pioneering teraops architectures and creating scientific datasets of unprecedented size. For this reason, Dr. Gilbert Weigand, leader of DOE's ASCI effort, launched this series of workshops, and backed them up with a commitment to support this line of research and development.
} 
- Newly interacting groups

- Time-critical decision

- One-time decision

- Multi-day 24 hour/day operation

- Baseline decision process (New technologies cannot upset this)

- Common perspective among participants

- Same fused data

- Same overview information

- Individual decision maker needs

- Customized requests for new data/analysis (Use staff support through verbal requests; Use computer support through workstations)

- Convergence toward course of action

- Assimilate information and iterate as required

- Make final decision

- Required new functionality

- Instant replays

- Simultaneous language translation

- Real-time data fusion

- Psychological analysis (e.g., voice stress)

- Interaction preservation

- Real-time caucus capability (private sidebars)

\section{B.2.c. Scenario}

In June of 2002 intelligence reports indicate the presence of a crude nuclear device in Cuba. Some aspects of the device are known and intelligence indicates its use against the US is imminent. POTUS must decide how to respond. She has an extremely broad range of options she can take. A geographically distributed National Security meeting is called that will continue for the duration of the crisis. The participants include the President (who will make any final decision), the Joint Chiefs (who will provide military options), the intelligence community, DOE and DOD sites (who must analyze the potential threat posed by the device), and others as needed.

The most important question is if and when the device can be used against the US. All information about the device (fissile material, quantity, quality, manufacturing processes and tolerance, etc.) is fed to the DOE DP Labs for analysis. They need to compute its yield and its weight.

Simultaneously, POTUS must begin fleshing out her options. There are both political and military responses. Military options include: a conventional surgical strike aimed at destroying the device, a nuclear strike that increases the probability of its destruction, or a military invasion. A conventional surgical strike requires knowledge of the location and the structure of the bunker in which the device is held. Engineers must model the behavior of penetrating bombs to see if they can both reach the target and destroy it. Furthermore, a tropical storm is approaching the island and cloud cover will preclude laser illumination of the target. Highly accurate weather prediction is needed if bombers are to be over the target when it is not occluded.

If a conventional option is rejected and the threat justifies a nuclear response, modeling of the target is again critical to allow a device with the minimum yield to be used to minimize collateral damage. Modeling the dispersion of radioactive debris is necessary to determine if it will be necessary to evacuate southern Florida. It will also be necessary to minimize political opposition in surrounding Caribbean nations.

If the location of the device cannot be determined or if further action is needed, the US may have to conduct an invasion of the island. This will require campaign planning, gaming of multiple scenarios, planning of logistics (optimization of routes, flow, etc.), and more. Finally, international allies must be consulted to steer their response and to gauge their willingness to cooperate, should an economic or political response be deemed more appropriate.

The time-critical nature of a decision precludes physically bringing all participants together. Scientists need to be close to simulation facilities; results must be transmitted to decision makers in real time. 
The human process of making a decision like this has been well established by thousands of years of evolution of Western culture, leadership, and military doctrine. First, the decision maker and his aids are brought together (figuratively if not literally). All existing data from multiple sources (both modeled and real) are fused to provide a common perspective. Then, the principals query the sources and bring additional data from their fields of expertise to bear to flesh out the situation. Finally, options are evaluated and the decision maker begins to converge on a course of action. The process will iterate throughout the crisis as actions taken and new intelligence continually change the underlying situation.

Technology cannot effectively change this process, but it can dramatically aid it. Below is description of how technology can help POTUS and her advisors assimilate the information presented to them and come to an optimal decision. DSWA (whoever) will direct the DOE DP labs to evaluate the likely yield of the Cuban nuclear device. This requires the use of the most powerful computing assets, which are remotely located. A likely result is that the inadequate knowledge of the device and differences in the models used by analysts will result in contradictory predictions of its yield. These must be resolved rapidly, in what will undoubtedly be acrimonious discussions between geographically distributed domain experts. Each will have the opportunity to present his case augmented in a design-review-like manner. Participants at each site will sit in immersive environments to review the massive amounts of simulated data. Fusion of the results of multiple experiments and simulations will be necessary to come to a consensus that the scientists can take to their less sophisticated military and political leaders.

Immersive displays in the conference rooms will be critical to quickly educate the leadership as to the likely yield of the Cuban device. The same displays will also be useful in presenting the results of damage assessment modeling for convention and nuclear strikes as well as weather prediction. The better these displays, the higher the confidence the leadership will have in the information presented, which, in turn, will lead to a more rapid convergence on a course of action.

The participants must be able to view each other and hear each other converse in real time. This is not art (à la Bran Ferrin), and the highest possible resolution is necessary for participants to evaluate the veracity of presenters, their data, and their conclusions. Automated aids for psychological analysis of participants may be helpful, and these will require high-resolution video and audio channels. Reactions are important from other participants, so each viewer must be able to steer among video streams drawn from the other participants.

Caucuses pre-exist among domain experts and will dynamically be generated during the decision-making process. Tools to allow private sidebars (whispers) are needed. These must be secure to allow highly sensitive information to be discussed. In fact, communications must have encryption the full link B/W. Because coalition allies may be involved, simultaneous translation must be provided.

There must be multiple sources of data brought to each decision-making participant by his supporting organization. Technically savvy participants may need their own workstations in front of them. Others will have aides in the immediate vicinity who can initiate queries and gather data. Some of this may be automated. Key words can be automatically extracted from the dialog and Web searches initiated to cache related information that may be needed in the immediate future. When Fidel Castro is first mentioned, his biography, knowledge of his health, intelligence on his whereabouts, etc. can all be cached for immediate recall if needed. In the case of geographical, weather, engineering, or imagery data, this could involve huge amounts of data speculatively pre-fetched.

\section{B.2.d. Technology Requirements}

\section{- Multiple HDTV image data streams}

- One per relevant face?

- Sound quality?

- Total data display size and resolution

- PowerWall

- Immersive/VR

- QoS

- Guaranteed bandwidth

- Guaranteed low (or no) latency

- Jitter control 
- Security

- Dynamic need-to-know groups

- Line speed encryption

- Speculative pre-fetch/caching

— Intelligent, automated micro-colonels (agents)

\section{B.3. Remote Interactive Computing Scenario}

\section{B.3.a. Requirements}

- Remote interactive execution of large-scale simulation

- Remote interactive access to large-scale simulation facilities

- Interactive steering of computations occurring both locally and remotely

- Appropriate GUIs and visualization facilities for this

\section{B.3.b. Assumptions}

- Theme: Remote large-scale computational field problems

Create a scenario that has a large number of application areas of interest to a large number of funding agencies. By choosing large-scale computational field problems as the overarching theme, it is then (hopefully) possible to re-cast the specific scenario by changing only a few key terms.

- Application areas

- Computational fluid dynamics

- Computational electromagnetics

- Computational combustion

- Computational mechanics

- Climate modeling

- Weather simulation

- Computational medicine (biofluids, bioelectric/magnetic fields, biomechanics, etc)

- Many more

- Programs

- DOE ASCI Laboratories

- DOE ASCI University Centers

- DOE SSI

- NSF PACI

- NIH Biomedical Computing

- NIH NCRR

- Large-scale computational field problems are defined here as the computational solution of boundary value problems (in which the governing physics is expressed as partial differential equations) within realistic geometric domains with realistic physics/chemistry/biology. An algorithm for solving large-scale computational field problems usually involves:

- Creating a discrete version of the physical domain; i.e., mesh generation, CAD

- Apply boundary conditions and material properties to the domain

- Numerically approximate the governing field equations; i.e., finite elements, finite differences, multi-grid

- Solve the resulting set of linear (or nonlinear) equations

- Visualize results

— Validate model and results

This algorithm is often repeated many times, changing physical and numerical attributes, such as mesh, boundary conditions, material properties, preconditioners, solvers, visualization technique, etc. One can envision a "computational workbench" that contains various application and middleware "toolkits" that a computational scientist uses to construct the models and simulation parameters, computes over a heterogeneous distributed system via the middleware, and interactively visualizes models and results in an augmented visualization environment situated locally at the scientist's office/lab. (This scenario is written so that it can be easily modified/augmented.) 


\section{B.3.c. Scenario: Computational Flow Around a Projectile/Airfoil/Heart Valve}

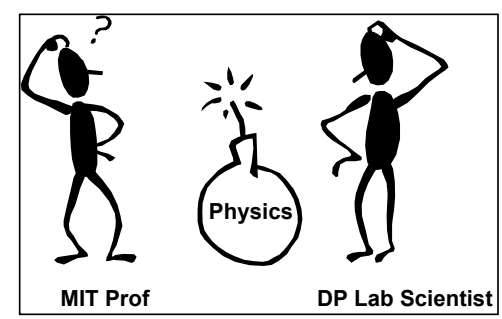

While visiting an East coast university faculty member regarding a collaborative research project, a DOE/NSF/NIH computational scientist becomes interested in pursuing questions that arise during their ensuing conversation. To answer the questions, the computational scientists decide to recompute portions of their previous CFD simulations and to try out new boundary conditions and different material properties.

The simulation concerns computing the flow around a projectile/airfoil/heart valve. Because of the complex geometry and flow speed, there is turbulence

near a critical region of the geometric design. It is crucial to obtain the correct flow parameters in order to design the proper projectile/airfoil/heart valve. In order to achieve an accurate answer, multi-resolution meshes are created that adapt in both time and space. In order to capture the multi-physics and complicated geometry, the highest resolution grid contains 500 million nodes, requiring 20 TB of memory and $100 \mathrm{~TB}$ of disk (assuming a $3 \mathrm{X}$ compression) running on a 10 teraflop machine at DOE/NSF/NIH for three days.

In order to obtain answers to their "what if" scenarios in near real time, the computational scientists reduce the overall size of their computational grid in an adaptive way, concentrating the most degrees of freedom near the critical region of geometry. Since the mesh is hierarchical and the highest resolution mesh was computed previously, the scientists can easily recreate a smaller mesh in near real time by resetting mesh parameters. The computational scientists then start up the flow simulation. They plan to compute the simulation on the remote DOE/NSF/NIH computer while sending portions of the updated simulation results to be visualized locally on the faculty member's responsive workbench. The responsive workbench features high-resolution immersive collaborative interaction so they can try out many different parameters and interactively manipulate the projectile/airfoil/heart valve geometry and view the results of their parameter/geometry changes and steer simulation results.

To interactively view their model and results on the responsive workbench, they require 120 frames per second for dual point-of-view stereo. After trying to interactively change the projectile/airfoil/heart valve geometry, a window pops up a message that informs them that the current computing resource will soon load another large-scale job such that they will not be able to obtain 120 frames per second. The window gives them the following options:

- Reduce the required number of frames per second

- Reduce the resolution of their model

- Move part of their job to a different computing resource (and lists options)

The scientists decide that they have already reduced the resolution as much as possible and need the interaction to effectively explore the simulation results and detail of the model geometry. Therefore, they decide to move part of their simulation to a different computing resource at DOE/NSF/NIH. The middleware toolkit pops up a window that gives specific information about the current bandwidth and latency of the new resources they will need to in order to obtain the specified performance. It also notes now much of the researchers' allocations will be needed to finish the computation. The scientists continue on their way, performing "what if" scenarios, interacting with their models and interactively viewing their simulation results.

During their meeting, a graduate student appears with a new software module that computes the flow using a new space-time multi-resolution algorithm. The faculty member drops the new module into their computational workbench environment and replaces the current simulation module with the new multi-resolution module. The module is dynamically linked in, such that they can continue their simulation; however, upon trying out the module, a window pops up with an error message noting that a fault has occurred and recommends a particular fault recovery strategy. The researchers agree to follow through with the recommended fault recovery strategy and fire up a profiling/probing module in order to look at the performance of the new multi-resolution flow module.

After a few more hours of pursuing "what if" scenarios, the researchers conclude that indeed, changes to the design were necessary in order to achieve an optimal design. 


\section{B.4. Remote Visualization Scenarios}

The original intent was to have one scenario on Remote Visualization, but after discussion, it was deemed that the requirements for Remote Immersive Visualization and Remote Scientific Visualization were different enough that two scenarios were warranted.

\section{B.4.a. Requirements}

\section{- Remote access to high-end DVC visualization facilities}

- Access and visualization of very-large-scale remote datasets

- Shared rendering/computation, using both local and remote computing resources

- Progressive rendering, image-based rendering, latency management, etc.

\section{B.4.b. Assumptions}

- Data too large (it cannot be moved)

- Heterogeneous environment

- Lab or office setting

- $\quad 2-5$ users, 2 head-tracked users at a time

- High-end university workstation

\section{B.4.c. Scenario: Remote Immersive Visualization}

A DP scientist is visiting several high-end universities to discuss with 2-5 colleagues the interaction of shocks with material crystals in a detonation front. In addition to the usual videos, a newly developed remote-VR system based on reduced compressed geometry, real-time delivery of high-definition 2D frames and image-based rendering techniques, allows small groups of faculty and students to interactively explore the 150-million cell simulation results. With this new VR system, any standard graphics workstation can perform the head tracking and local operations needed, while a remote "compute/data manipulation engine" at one of the DP labs serves the data required over a wide-area network at interactive speeds.

The VR head-tracking system must accommodate at least $12 \mathrm{~Hz}$ to prevent unpleasantness for the users, however 25 $\mathrm{Hz}$ to $60 \mathrm{~Hz}$ is desired. (This implies a lag of $<50-70 \mathrm{~ms}$ between the movement of a head muscle until an updated photon from the screen reaches the user's eye). The $2 \mathrm{~K} \times 2 \mathrm{~K}$ stereo display target update rate is 30 frames per second for each eye. The haptics device update loop operates at $1000 \mathrm{~Hz}$ using a local force-torque array data subset. The system supports $5-10 \mathrm{~Hz}$ updates from the data server.

The scientists find that observing such phenomena via an interactive VR system is quite different and complementary to the usual false color videos. The videos are excellent at giving an overview of the simulation. But, the VR system lets one fly through the data and look at the shocks diffracting off individual crystals, giving a much greater sense of the fidelity of the simulation than one gets from simple videos. Moreover, 3D phenomena, which are difficult to understand from $2 \mathrm{D}$ videos, are now comprehensible.

\section{B.4.d. Scenario: Remote Scientific Visualization}

At the Allied Signal Plant in Kansas City, a manufacturing engineer is preparing for a short manufacturing run on a safety component. She is currently considering the curing of a potting agent in a radiant oven. From her high-end $\mathrm{PC}$, she is designing the heating profiles and component layouts in the oven. Her computations and visualizations are supported by a local compute and data server and by ASCI-scale machines at the DP labs, based on the meshes, boundary and initial conditions she is preparing on her PC. She really appreciates the run-time visualization, which allows her to detect problems in each run without waiting for the entire run to complete.

The analysis requires her to compute several derived quantities, as the calculation considers electrical power, while the control value to the oven is amperage. She also requires temperature history plots at several key locations in the component. To fully understand the curing process, she is extensively using cut planes, isosurfaces and volume visualization, updated at a rate of $5-10 \mathrm{~Hz}$ on the data server. 
At the water cooler, her manager explains how just 10 years ago a small manufacturing run would not have been possible because more components that the entire run would have to be wasted simply to develop the process. She recommends to her manager that the next purchase of ovens have some of the heating elements relocated to provide improved control of the oven.

\section{B.4.e. Technology Requirements}

\section{Data Server to Workstation}

- Compute spectrum

- Pre-compute (Juke box)

- Real-time computation

- Send

- Reduced geometry

- Images

- Distance insensitivity

Workstation to Eye

- Head tracking for two users

- Head tracking

- $<12 \mathrm{~Hz} \rightarrow$ sick

- 20-30 Hz need

- $60+\mathrm{Hz}$ desired

- Haptics (bonus)

- Immersion

- Head tracked stereo and wide FOV

- Lag (latency) defined

- Head muscle moves until photon hits eye

- Two types of lag

- Head tracking 50-70 ms

- New geometry (slower 5-10 Hz)

- Immersion is level of quality

\section{B.5. Remote Virtual Prototyping and Design Scenario}

\section{B.5.a. Scenario}

The engineering task is to design an improved Wankel engine for use in remote-piloted aircraft flying at altitudes in excess of 100,000 feet. The optimization criteria include high efficiency and low weight, constrained by a hostile operating environment. Because of these constraints, the engine must be built with advanced materials and incorporate state-of-the-art technical enhancements. To complete the design, experts in several disciplines (including combustion, fluid dynamics, materials science, thermodynamics, and manufacturing) collaborate in a virtual environment. The environment uses an instrumented room to project images of all meeting participants on convenient surfaces, rather than on a separate screen (giving a greater impression of presence to all involved). For the most part, the engine has not been built physically yet, so the virtual environment also gives "reality" to the design by a combination of high-resolution visualization and haptic-feedback devices. A central database stores the model, which consists of a solid model for the parts, materials specifications for each part, and information needed to generate analysis meshes. Because there is substantial experimental data on previous engine models, an additional "experiments" database is also available as a check on (and sometimes substitute for) simulation data. The environment provides a common visualization of this model that all participants can share. They can also overlay their own views with domain-specific visualization on their local projection. This allows a common basis for discussion, while allowing detailed information for the specialists. Of course, specialists can share their view with other meeting participants if needed. Participants have sets of domain-specific tools at their disposal, which all work from a common parameterized model. Because all tools work from the same model, there is a high degree of interoperability among the tools; analyses from interacting components can be interfaced with little difficulty. 
As an example of the design process, we consider a late requirements change to the engine. When new external constraints require reducing the engine weight by a small amount without significant redesign, the following might occur:

- A subset of the design team, comprised of the product engineer, mechanical designer, thermodynamicist, and manufacturing engineer meet in the virtual space and create local copies of the current design.

- The thermodynamicist suggests reducing the size of a structural member adjoining the combustion and cooling spaces of the engine. This kills two birds with one stone-it improves the cooling performance (already a problem), and reduces weight (the new constraint).

- The mechanical designer notes that the suggested redesign is not feasible, since the member will now fail when the engine is run at high speed. He illustrates this with a coarse-resolution simulation showing the stresses in the engine. The thermodynamicist agrees to a smaller reduction.

- The manufacturing engineer completes a more detailed simulation (run remotely in order to take advantage of more computing capacity) and reports that even the new redesign is not feasible. The thinness of the structural member will not support the milling necessary to provide the specified finish on an adjoining part. He gives the group a choice: either use a higher tolerance on the finish or work on a different structural member.

- The simulation of finish would be too computationally demanding to complete in real time. However, the experiment database has several suggestive datapoints that indicate that finish is not key to performance in this part of the engine. After querying the experiments, the group decides to tentatively accept the new finish but to submit a detailed simulation experiment to verify their solution. The next time this issue comes up, the simulation results will be available to answer it more directly.

- The weight goal has still not been met, so the group searches for other opportunities for redesign. A similar back-and-forth process continues until the design is complete.

\section{B.5.b. Technology Requirements}

- Interaction: 3 to 5 sites are linked by virtual reality conferencing

- VR representation of the "shared space"-24 Gbps per room (as per the decision-making scenario)

- VR representation of the engine to be derived from the shared model. No additional data handling requirements. We assume visualization of the model itself is done locally, so there are no "distance" issues.

- Haptic feedback for engine model — share a reduced model, render locally. (This avoids difficulties with latency in haptic feedback.) Assuming a $100 \times 100 \times 100$ discretization with 6 variables (force and torque in each dimension) of interest, this requires $12 \mathrm{MB}$ of data to be exchanged within a few seconds (to avoid undue waiting by the participants). Estimated bandwidth requirements: 6 Mbps (in bursts).

- In essence, these are the same requirements for the shared decision meeting scenario, with an additional requirement for a haptic interface.

- Modeling: Shared model of engine

- CAD model: 1000 parts, $5 \mathrm{MB}$ total storage downloaded at beginning of meeting, and updated for every new design. To keep the discussion interactive, each update must take no more than a few seconds. Estimated bandwidth requirements: 5 MBps.

- Materials information: $5 \mathrm{MB}$ of available materials downloaded once at beginning of meeting. Bandwidth requirements: insignificant.

- Meshing information: $100 \mathrm{MB}$ (unstructured) finite element model of engine, $100 \mathrm{MB}$ CFD mesh both downloaded at beginning of meeting, and updated or regenerated for every new design. Estimated bandwidth requirements: $100 \mathrm{MBps}$.

\section{- Simulations}

- Domain-specific simulations done locally based on common model (for small- to medium-granularity analysis). This requires generating the simulation mesh from the shared model. Estimated bandwidth: 0 MBps (if meshing is done locally) to $100 \mathrm{MBps}$ (if meshing is done remotely).

- Larger simulations may be done remotely, where substantial computation is available. The bandwidth required is between the data manager and the computational resource. Estimated bandwidth requirements: 0 MBps (if simulations are collocated with all data) to infinity (if diverse remote data sources and meshes must be used). 
- Coupled simulations require sharing interface information. Meshes or boundaries may be exchanged repeatedly to solve coupled analysis problems. Estimated bandwidth requirements: 1GBps for coupled simulations (assuming 2 simulations not collocated). 


\section{Road Maps}

\section{C.1. What is a Road Map?}

There are four major DVC/Distance technology areas we cover:

- Networking and QoS

- $\quad$ Remote Computing

- $\quad$ Remote Visualization

- $\quad$ Remote Data

Each "road map" consists of two parts, a "functionality" matrix (what can be done) and a "technology" matrix (underlying technology). That is, functionality matrices show the desired operational characteristics, while technology matrices show the underlying technology needed. In practice, there isn't always a clean break between "functionality" and "technology," but it still seems useful to try and separate things this way.

\section{C.2. Networking and QoS Road Map}

\section{C.2.a. DVC Possible WAN Interconnection Points}

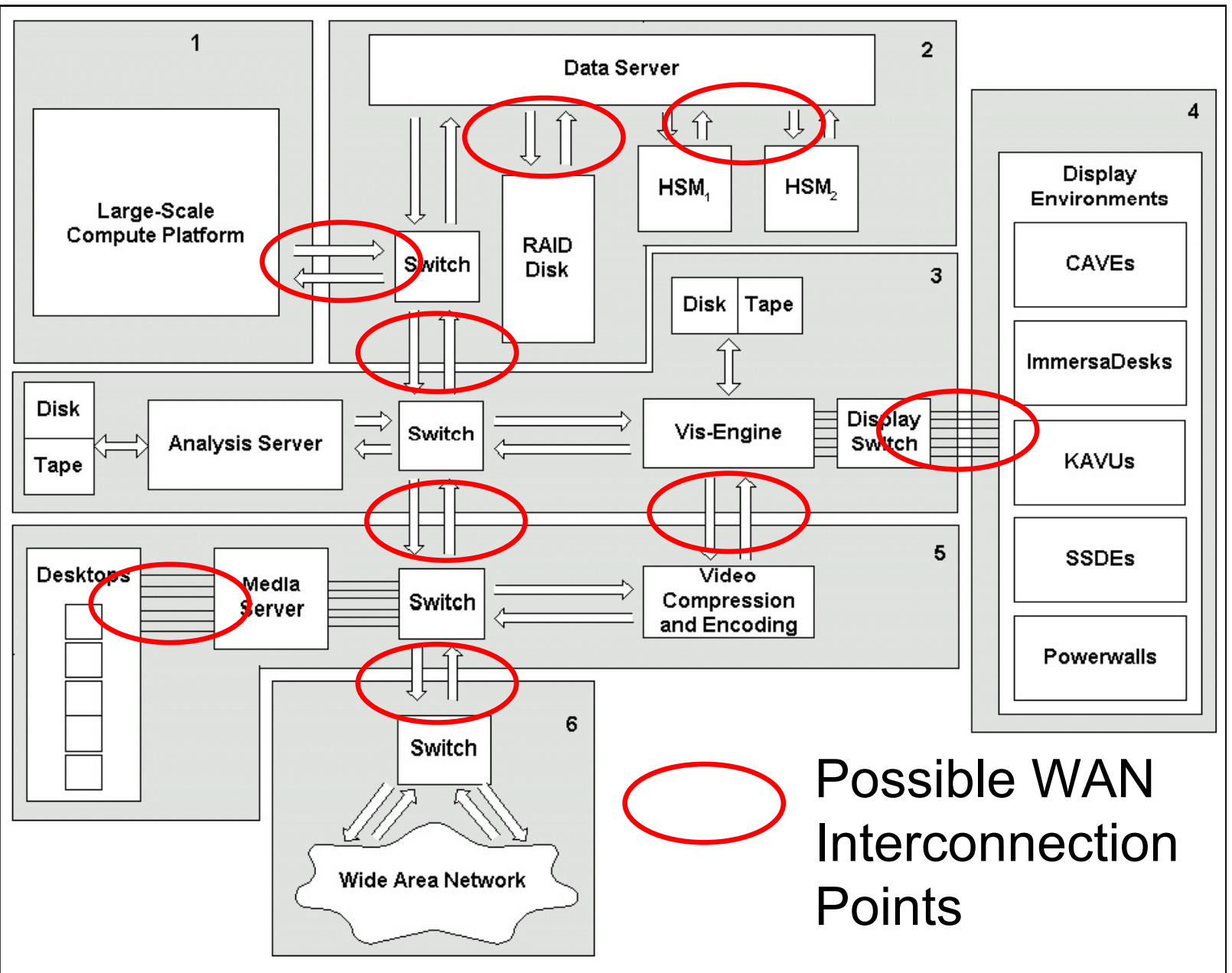


C.2.b. Networking Technology Road Map

\begin{tabular}{|c|c|c|c|}
\hline \multicolumn{4}{|c|}{ Networking Technology Road Map } \\
\hline & 1999 & 2001 & 2004 \\
\hline $\begin{array}{l}\text { Interconnect } \\
\text { Network-MP }^{2}\end{array}$ & $100-200 \mathrm{M}$ & $400 \mathrm{M}$ & $800 \mathrm{M}$ \\
\hline $\begin{array}{l}\text { System Area } \\
\text { Network }^{3}\end{array}$ & $800 \mathrm{M}$ & $800 \mathrm{M}$ & $1600 \mathrm{M}$ \\
\hline $\begin{array}{l}\text { Local Area } \\
\text { Network }^{4}\end{array}$ & $1 \mathrm{Gbps}$ & $1 \mathrm{Gbps}$ & $10 \mathrm{Gbps}$ \\
\hline $\begin{array}{l}\text { Metropolitan Area } \\
\text { Network }^{5}\end{array}$ & OC-192 & OC-768 & OC-768 \\
\hline $\begin{array}{l}\text { Wide Area } \\
\text { Network- }^{\text {Experimental }}{ }^{6}\end{array}$ & OC-192 & OC-768 & OC-3072 \\
\hline $\begin{array}{l}\text { Wide Area } \\
\text { Network- } \\
\text { Production }^{7}\end{array}$ & OC-48 & OC-192 & OC-768 \\
\hline $\begin{array}{l}\text { Wide Area } \\
\text { Bandwidth } \\
\text { Aggregate }^{8}\end{array}$ & 40 Gbps & $160 \mathrm{Gbps}$ & $640 \mathrm{Gbps}$ \\
\hline $\begin{array}{l}\text { Single Channel } \\
\text { Interface Speeds }\end{array}$ & $2.4 \mathrm{Gbps}$ & $10 \mathrm{Gbps}$ & $40 \mathrm{Gbps}$ \\
\hline $\begin{array}{l}\text { Number of } \\
\text { Channels } \\
\text { (DWDM) }^{10}\end{array}$ & 4-40 WDM & 16-64 WDM & 32-128 WDM \\
\hline \multicolumn{4}{|l|}{ Protocols } \\
\hline IP & PPP/SONET and IP/ATM/SONET & IPv6 over SONET (PTP) & $\begin{array}{l}\text { IP over WDM with channel } \\
\text { bonding }\end{array}$ \\
\hline HIPPI & $\begin{array}{l}\text { Move from HIPPI- } 800 \text { to HIPPI- } \\
6400\end{array}$ & IP/HIPPI/SONET & \\
\hline ATM & WAN and some LAN & Phased out in LAN GigaEthernet & $\begin{array}{l}\text { Phased out in favor of IP/SONET } \\
\text { in WAN }\end{array}$ \\
\hline PPP & Over SONET for high-speed PTP & Basis for QoS and ST type work & PPP over WDM \\
\hline $\begin{array}{l}\text { Scheduled } \\
\text { Transport }\end{array}$ & $\begin{array}{l}\text { Basis for SAN I/O and cluster } \\
\text { networks }\end{array}$ & $\begin{array}{l}\text { Integration with MPI and shared } \\
\text { memory programming models }\end{array}$ & $\begin{array}{l}\text { Wide-area extensions for remote } \\
\text { data access }\end{array}$ \\
\hline VIA & Low end SAN memory to memory & $\begin{array}{l}\text { Integration with MPI and shared } \\
\text { memory programming models }\end{array}$ & $\begin{array}{l}\text { Wide-area extensions for remote } \\
\text { data access }\end{array}$ \\
\hline $\begin{array}{l}\text { OS-Bypass } \\
\text { Technology }\end{array}$ & Experimental & Production & Second generation \\
\hline $\begin{array}{l}\text { Parallel IP and } \\
\text { Channel Bonding } \\
\end{array}$ & Ad hoc techniques, 8-way & $\begin{array}{l}\text { Integrated with IP stack and OS, } \\
\text { scalable to 16-way }\end{array}$ & Scale to 128 -way parallelism \\
\hline \multicolumn{4}{|c|}{ Network Interface Cards } \\
\hline Commodity PC & $\begin{array}{l}\text { GigaEthernet, OC-12 ATM, } \\
\text { Myranet-2 }\end{array}$ & OC-48 & OC-192, 10 GigaEthernet \\
\hline $\begin{array}{l}\text { High-End } \\
\text { Workstations } \\
\end{array}$ & GigaEthernet, OC-48 & OC-192, 10 GigaEthernet & OC-768? \\
\hline High-End Servers & $\begin{array}{l}\text { Multiple GigaEthernet, OC-48, } \\
\text { HIPPI-6400 }\end{array}$ & Multiple OC-192 & Multiple OC-768 \\
\hline \multicolumn{4}{|l|}{ Switches } \\
\hline
\end{tabular}

2 About right for IBM, Myranet low for memory-based systems

3 Check GigaEthernet and HIPPI 6400, FC, Myranet

4 Ethernet or ATM

5 Above OC-192 we assume WDM

6 Above OC-192 we assume WDM

7 Above OC-192 we assume WDM

${ }^{8}$ Assumes multiple WDM channels

${ }^{9}$ Assume WDM and GX like basis

${ }^{10}$ Do the math to get bounds above 


\begin{tabular}{|c|c|c|c|}
\hline Size $^{11}$ & $32 \times 32$ & $64 \times 64$ & $128 \times 128$ \\
\hline $\begin{array}{l}\text { Bisection } \\
\text { Capacity }^{12} \\
\end{array}$ & $40 \mathrm{~Gb}$ & $160 \mathrm{~Gb}$ & $\mathrm{~Tb}$ \\
\hline Buffers (Cells?) ${ }^{13}$ & $1 \mathrm{~GB}$ & $16 \mathrm{~GB}$ & $64 \mathrm{~GB}$ \\
\hline $\begin{array}{l}\text { Size or Routing } \\
\text { Tables }\end{array}$ & $100 \mathrm{~K}$ routes & $10 \mathrm{M}$ routes & $1 \mathrm{~B}$ routes \\
\hline \multicolumn{4}{|c|}{ Provisioning and Network Setup } \\
\hline $\begin{array}{l}\text { Provisioning and } \\
\text { Network Setup }^{15}\end{array}$ & Ad hoc schemes and manual setup & Bandwidth brokerage services & $\begin{array}{l}\text { Application transparent (dynamic } \\
\text { provisioning) }\end{array}$ \\
\hline \multicolumn{4}{|l|}{ QoS Capabilities } \\
\hline QoS Capabilities & $\begin{array}{l}\text { Two streams, best effort and better } \\
\text { effort }\end{array}$ & $\begin{array}{l}4 \text { classes, constant bit rate, highest } \\
\text { priority, variable high, variable } \\
\text { bulk, variable size express }\end{array}$ & $\begin{array}{l}4 \text { classes as before plus multicast } \\
\text { support etc. }\end{array}$ \\
\hline Number of Classes & 2 & 4 & 8 \\
\hline Setup Mechanisms & Ad hoc & Broker based automagic & Dynamic adaptive \\
\hline QoS Routing & $\begin{array}{l}\text { Experimental, IETF working } \\
\text { group, definition stage }\end{array}$ & Usable in restricted domains & $\begin{array}{l}\text { Broadly deployed in private } \\
\text { networks }\end{array}$ \\
\hline $\begin{array}{l}\text { Mapping QoS to } \\
\text { Protocols }\end{array}$ & $\begin{array}{l}\text { Experimental ATM to IP } \\
\text { mappings, early work on QoS over } \\
\text { WDM }\end{array}$ & $\begin{array}{l}\text { Implemented in edge devices, } \\
\text { RSVP and wireless, more } \\
\text { mappings }\end{array}$ & $\begin{array}{l}\text { Deployed in private networks, } \\
\text { integration with network } \\
\text { management }\end{array}$ \\
\hline $\begin{array}{l}\text { Advanced } \\
\text { Reservations }\end{array}$ & \begin{tabular}{|l|} 
Definition stage \\
\end{tabular} & $\begin{array}{l}\text { Experiments supporting } \\
\text { metacomputing }\end{array}$ & \begin{tabular}{|l|} 
Reservations for bandwidth \\
\end{tabular} \\
\hline $\begin{array}{l}\text { Bandwidth } \\
\text { Brokerage }^{16}\end{array}$ & $\begin{array}{l}\text { Definition of mechanisms for } \\
\text { automatic negotiation of } \\
\text { bandwidth agreements }\end{array}$ & $\begin{array}{l}\text { Trials and experiments, point to } \\
\text { point, point to multipoint }\end{array}$ & Availability in private networks \\
\hline \multicolumn{4}{|l|}{ Traffic Shaping } \\
\hline Traffic Shaping $^{17}$ & Application based & $\begin{array}{l}\text { Local aggregator based-with } \\
\text { AUX service support }\end{array}$ & Application transparent \\
\hline \multicolumn{4}{|l|}{ Traffic Policing } \\
\hline Traffic Policing $^{18}$ & $\begin{array}{l}\text { Gateway based but viewed as a } \\
\text { network service }\end{array}$ & $\begin{array}{l}\text { Local aggregator based-with } \\
\text { AUX service support }\end{array}$ & Application transparent \\
\hline \multicolumn{4}{|c|}{ System Engineering and End-to-End Performance } \\
\hline $\begin{array}{l}\text { System } \\
\text { Engineering and } \\
\text { End-to-End } \\
\text { Performance } \\
\end{array}$ & $\begin{array}{l}\text { Prototype architecture and } \\
\text { mechanisms to support end-to-end } \\
\text { performance }\end{array}$ & $\begin{array}{l}\text { Experiments validating end-to-end } \\
\text { performance architecture and } \\
\text { functionality }\end{array}$ & $\begin{array}{l}\text { Begin deployment of end-to-end } \\
\text { infrastructure }\end{array}$ \\
\hline \multicolumn{4}{|l|}{ Security } \\
\hline $\begin{array}{l}\text { Link Level } \\
\text { (SONET) }\end{array}$ & OC-48 & OC-192 & OC-192 \\
\hline ATM Encryption & OC-12 & OC-48 & OC-192 \\
\hline IP Encryption $^{20}$ & OC-3 & OC-12 & OC-48 \\
\hline $\begin{array}{l}\text { Single Sign-on/ } \\
\text { Public Key }\end{array}$ & Experimental infrastructure & Prototype infrastructure & Production infrastructure \\
\hline \multicolumn{4}{|l|}{ Multicast } \\
\hline Multicast & IP based using TTL & $\begin{array}{l}\text { IP based using something better } \\
\text { than TTL }\end{array}$ & $\begin{array}{l}\text { Network topology based } \\
\text { segmentation }\end{array}$ \\
\hline ATM & Supports vLANs & Integrated with IP & \\
\hline
\end{tabular}

\footnotetext{
${ }^{11}$ Off the shelf

${ }_{13}^{12}$ Nortel, Cisco road maps?

${ }^{13}$ Check this

${ }^{14}$ Check this

${ }^{15}$ Flesh out details

${ }^{16}$ Wide availability dependent on gap between commodity network and private networks

${ }^{17}$ Mixing streams to form agreed injection mix

${ }^{18}$ Enforcing agreed injection mix

${ }^{19}$ Need to address storage, memory, CPU scheduling, bandwidth in SANs and graphics performance, etc.

${ }^{20}$ Motorola
} 


\begin{tabular}{|l|l|l|l|} 
Reliable & Application level overlay layer & Router and QoS support & $\begin{array}{l}\text { Production availability in private } \\
\text { net }\end{array}$ \\
\hline Unreliable & Router supported & QoS integration & $\begin{array}{l}\text { Production availability in private } \\
\text { net }\end{array}$ \\
\hline Virtual LANs and Secure Tunnels & \begin{tabular}{l} 
Integrated with QoS routing and ?? \\
\hline $\begin{array}{l}\text { Virtual LANs and } \\
\text { Secure Tunnels }\end{array}$
\end{tabular} & $\begin{array}{l}\text { Experimental prototypes available } \\
\text { but not integrated with QoS }\end{array}$ & $\begin{array}{l}\text { Integrate vLANs QoS and } \\
\text { brokering. }\end{array}$ \\
\hline
\end{tabular}

\section{C.2.c. Bandwidth Requirements}

\begin{tabular}{|l|l|l|l|}
\hline \hline Bandwidth Requirements \\
\hline Type of Interaction & \# Simulations & Bandwidth & Rationale \\
\hline \hline Computations & $1-3$ & $100 \mathrm{Gbps}-1 \mathrm{Tbps}$ & $1 \%-10 \%$ of bisection bandwidth \\
\hline Real-Time Steering & $2-10$ & $10 \mathrm{Gbps}$ & 4 screens $\mathrm{x} 160$ frame rate $\mathrm{x} 4 \mathrm{Kx} 4 \mathrm{~K}$ pixels $\times 32$ \\
\hline Remote Visualization & $2-10$ & $10 \mathrm{Gbps}$ & \\
\hline Remote I/O & & & \\
\hline Navigation & $2-3$ & $30 \mathrm{Gbps}-600 \mathrm{Gbps}$ & $600 \mathrm{~TB}$ in 55 hours \\
\hline Collaboration & $5-20$ & $1 \mathrm{Gbps}-5 \mathrm{Gbps}$ & $128^{\wedge} 3 * 8=16 \mathrm{MB} \times 30 \Rightarrow 500 \mathrm{MB} \Rightarrow 5 \mathrm{~Gb}$ \\
\hline Instruments & $30-60$ & $100 \mathrm{Mbps}-1 \mathrm{Gbps}$ & 9 -video, stereo audio \\
\hline
\end{tabular}

\section{C.2.d. Tele-Immersion Networking Requirements}

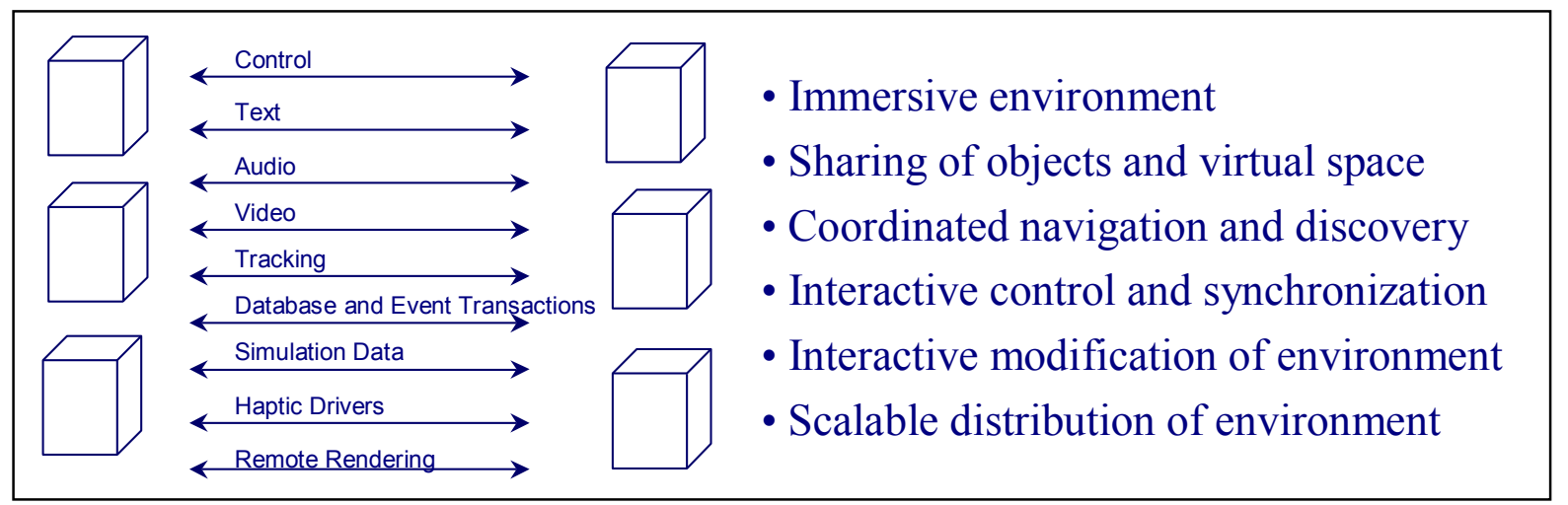

\begin{tabular}{|l|l|l|l|l|l|l|l|}
\hline \hline \multicolumn{7}{|l}{ Tele-Immersion Data Flow Types } \\
\hline Type & Latency & Bandwidth & Reliable & Multicast & Security & Streaming & Dyn QoS \\
\hline \hline Control & $<30 \mathrm{~ms}$ & $64 \mathrm{Kbps}$ & Yes & No & High & No & Low \\
\hline Text & $<100 \mathrm{~ms}$ & $64 \mathrm{Kbps}$ & Yes & No & Medium & No & Low \\
\hline Audio & $<30 \mathrm{~ms}$ & Nx128 Kbps & No & Yes & Medium & Yes & Medium \\
\hline Video & $<100 \mathrm{~ms}$ & Nx5 Mbps & No & Yes & Low & Yes & Medium \\
\hline Tracking & $<10 \mathrm{~ms}$ & Nx128 Kbps & No & Yes & Low & Yes & Medium \\
\hline Database & $<100 \mathrm{~ms}$ & $>1 \mathrm{G}$ & Yes & Maybe & Medium & No & High \\
\hline Simulation & $<30 \mathrm{~ms}$ & $>1 \mathrm{G}$ & Mixed & Maybe & Medium & Maybe & High \\
\hline Haptic & $<10 \mathrm{~ms}$ & $>1 \mathrm{Mbps}$ & Mixed & Maybe & Low & Maybe & High \\
\hline Rendering & $<30 \mathrm{~ms}$ & $>1 \mathrm{G}$ & No & Maybe & Low & Maybe & Medium \\
\hline
\end{tabular}

The columns represent flow-type attributes:

- Latency is the sum of all delays in the system, from the speed of light in fiber, to operating system overhead, to tracker settling time and screen refresh.

- Bandwidth is the bits/second the system can transmit.

- Reliable flows are verified and retransmitted if bad.

\footnotetext{
${ }^{21}$ Physical path routing data might be required here
} 
- Multicast flows go to more than one site at once.

- Security involves encryption overhead that may or may not be warranted or legal.

- Streaming data is a constant flow of information over time, as with video, audio and tracking.

- Dynamic QoS can provide ways to service bursty high-bandwidth needs on request

The rows indicate the data flow types:

- Control information consists of data that is used to manage the tele-immersion session, to authenticate users or processes, to launch processes, to control the display or tracking systems, and to communicate out of band between the world servers and VR systems.

- Text provides simple communications capability within collaborative sessions for simple note taking and passing. Text can also command Unix processes driving the environments.

- Audio gives ambient auditory cues, allows voice communications among users, and is used to issue commands via voice recognition and speech synthesis. A typical application may use multiple audio streams.

- Video can allow teleconferencing or remote monitoring displayed within the virtual world. Synthetic $2 \mathrm{D}$ animated bitmaps in video format have application as well.

- Tracking is achieved with location and orientation sensors, and captures the position and orientation of the user. Typically this data is streamed to the computer responsible for computing the perspective of the scene. Tele-Immersion requires tracking data to be shared among sites. Most VR systems only head and hand track; future systems will have many more sensors to track more complex posture and body motions.

- Database is the heart of a tele-immersion application world. The database contains the graphical models of virtual scenes, objects, and data, and since the database is used to provide the models that are rendered, it must be maintained in a coherent state across multiple sites. Databases might be as simple as shared VRML files or as complex as multi-terabyte scientific datasets, VR extensions of video serving, or even Virtual Director recorded sessions.

- Simulation provides the basis for dynamic behaviors, like responding to the users' actions. Small-scale simulations can often run on the computer also generating the VR experience, but frequently the simulation will need a dedicated supercomputer. User input is captured and transmitted to the simulation via the network and the simulation will generate an update, which is then propagated to each user site for local rendering. Typically the data transferred to the simulation is considerably smaller than the data returned by the simulation. For example if the user is conducting an interactive molecular docking experiment, only tracking data need be sent to the molecular model indicating the location of the users hand, however, in response, the simulation will return updated coordinates of hundreds or thousands of atoms.

- Haptics include force and touch sensing/feedback devices and use a variety of sensors and actuators that are "attached" to the hands, legs of the users. Some systems now generate haptic "images" that augment or replace visual images (e.g., a user feeling the magnetic field around a star simulation or perceiving the texture of an atomic scale surface being imaged by a scanning microscope). Haptics are particularly sensitive to latency and jitter (instantaneous variations in latency).

- Rendering is the transformation of geometric information (polygonal or volumetric) into images for display. All VR environments primarily render graphics locally. As networks provide bandwidth adequate for compressed HDTV, however, it will become reasonable and efficient for scenes to be rendered remotely and transmitted to each site in real time.

\section{C.2.e. Networking Requirements}

\begin{tabular}{|l|c|c|c|c|c|c|c|}
\hline \hline \multicolumn{1}{|c|}{ Interaction } & \multicolumn{2}{c|}{$\begin{array}{c}\text { \# Streams } \\
\text { (Gbps) }\end{array}$} & \multicolumn{2}{c|}{$\begin{array}{c}\text { Bandwidth } \\
\text { (Gbps) }\end{array}$} & \multicolumn{2}{c|}{$\begin{array}{c}\text { Aggregate } \\
\text { (Tbps) }\end{array}$} & $\begin{array}{c}\text { Average } \\
\text { (Tbps) }\end{array}$ \\
\hline \hline Steering & 2 & 10 & 1 & 10 & 0.002 & 0.1 & 0.03 \\
\hline $\begin{array}{l}\text { Remote High } \\
\text { Performance } \\
\text { Visualization }\end{array}$ & 2 & 10 & 1 & 10 & 0.002 & 0.1 & 0.03 \\
\hline $\begin{array}{l}\text { Remote Desktop } \\
\text { Visualization }\end{array}$ & 20 & 100 & 0.1 & 1 & 0.002 & 0.1 & 0.03 \\
\hline Remote Database & 20 & 100 & 0.1 & 1 & 0.002 & 0.1 & 0.03 \\
\hline Data Exploration & 5 & 20 & 0.5 & 5 & 0.0025 & 0.1 & 0.03 \\
\hline Collaboration & 30 & 60 & 0.1 & 1 & 0.003 & 0.06 & 0.02 \\
\hline Instrumentation & 10 & 20 & 0.08 & 5 & 0.0008 & 0.1 & 0.04 \\
\hline \hline Subtotal & $\mathbf{8 9}$ & $\mathbf{3 2 0}$ & & & $\mathbf{0 . 0 1}$ & $\mathbf{0 . 6 6}$ & $\mathbf{0 . 2 3}$ \\
\hline Remote I/O & 2 & 3 & 30 & 600 & 0.06 & 1.8 & 0.79 \\
\hline Computations & 1 & 3 & 100 & 1000 & 0.1 & 3 & 1.10 \\
\hline \hline Total & $\mathbf{9 2}$ & $\mathbf{3 2 6}$ & & & $\mathbf{0 . 1 7}$ & $\mathbf{5 . 4 6}$ & $\mathbf{2 . 1 2}$ \\
\hline \hline
\end{tabular}

Networking requirements are based on a preliminary understanding of how SSP users will collaborate and access computers and data. There are still many uncertainties; e.g., will we move data or process it remotely? Estimates are based on 2004 requirements.

There are four levels of bandwidth connectivity:

Tier 1 = Leading-Edge Sites (2-3 nodes) 
Tier 2 = Mid-Range (4-6 nodes)

Tier 3 = Data and Visualization Corridors (16-20 nodes)

Tier 4 = Collaboration Nodes (30-60 nodes)

\begin{tabular}{|l|c|c|c|c|}
\hline \hline & Tier 1 & Tier 2 & Tier 3 & Tier 4 \\
\hline \hline Tier 1 & $1 \mathrm{~Tb}$ & $100 \mathrm{~Gb}$ & $30 \mathrm{~Gb}$ & $1 \mathrm{~Gb}$ \\
\hline Tier 2 & $100 \mathrm{~Gb}$ & $100 \mathrm{~Gb}$ & $30 \mathrm{~Gb}$ & $1 \mathrm{~Gb}$ \\
\hline Tier 3 & $30 \mathrm{~Gb}$ & $30 \mathrm{~Gb}$ & $30 \mathrm{~Gb}$ & $1 \mathrm{~Gb}$ \\
\hline Tier 4 & $1 \mathrm{~Gb}$ & $1 \mathrm{~Gb}$ & $1 \mathrm{~Gb}$ & $1 \mathrm{~Gb}$ \\
\hline
\end{tabular}

\begin{tabular}{|l|c|c|}
\hline \hline & Aggressive & Conservative \\
\hline \hline Tier 1 & $1 \mathrm{~Tb}$ & $100 \mathrm{Gbps}$ \\
\hline Tier 2 & $100 \mathrm{~Gb}$ & $30 \mathrm{Gbps}$ \\
\hline Tier 3 & $30 \mathrm{~Gb}$ & $10 \mathrm{Gbps}$ \\
\hline Tier 4 & $1 \mathrm{~Gb}$ & $1 \mathrm{Gbps}$ \\
\hline
\end{tabular}

Some middleware requirements:

- Directory services for person, place and resources

- Authentication services

- Remote data access and communications services

- Co-scheduling of distributed resources (computers, networks, VR devices, instruments)

- Security and reliability in communications

- Multicast and efficient broadcast capabilities

- Multiple data stream management (requires QoS and support of multiple network channels)

- Low latency is as important as high bandwidth

\section{C.2.f. SuperCorridor Road Map}

\begin{tabular}{|c|c|c|c|c|c|c|}
\hline \multicolumn{7}{|c|}{ SuperCorridor Road Map } \\
\hline Feature and Function & Units & FY98 & FY00 & FY01 & FY03 & FY05 \\
\hline \multicolumn{7}{|l|}{ Example Application } \\
\hline $\begin{array}{l}\text { Total Memory Needed by } \\
\text { Application }\end{array}$ & Bytes & $200.0 \mathrm{E}+9$ & $600.0 \mathrm{E}+9$ & $3.0 \mathrm{E}+12$ & $6.0 \mathrm{E}+12$ & $12.0 \mathrm{E}+12$ \\
\hline \# Processors Used Per Run & Processors & $500.0 \mathrm{E}+0$ & $1.0 \mathrm{E}+3$ & $2.0 \mathrm{E}+3$ & $3.0 \mathrm{E}+3$ & $4.0 \mathrm{E}+3$ \\
\hline $\begin{array}{l}\text { Degree of Interactivity } \\
\text { (Response Time) }\end{array}$ & Seconds & 6.40 & 2.40 & 4.00 & 5.00 & 7.50 \\
\hline Typical Run Time & Hours & 8.89 & 6.67 & 22.22 & 55.56 & 166.67 \\
\hline $\begin{array}{l}\text { Number of Simulation } \\
\text { Time Steps per Run }\end{array}$ & Steps & $20.0 \mathrm{E}+3$ & $40.0 \mathrm{E}+3$ & $80.0 \mathrm{E}+3$ & $160.0 \mathrm{E}+3$ & $320.0 \mathrm{E}+3$ \\
\hline $\begin{array}{l}\text { Volume of Archival Data } \\
\text { (Diagnostic) }\end{array}$ & Bytes & $20.0 \mathrm{E}+12$ & $60.0 \mathrm{E}+12$ & $180.0 \mathrm{E}+12$ & $600.0 \mathrm{E}+12$ & $1.8 \mathrm{E}+15$ \\
\hline $\begin{array}{l}\text { Volume of Archival Data } \\
\text { (Prognostic) }\end{array}$ & Bytes & $200.0 \mathrm{E}+12$ & $600.0 \mathrm{E}+12$ & $1.8 \mathrm{E}+15$ & $6.0 \mathrm{E}+15$ & $18.0 \mathrm{E}+15$ \\
\hline $\begin{array}{l}\text { Number of Checkpoints } \\
\text { Per Run }\end{array}$ & Count & 20 & 40 & 80 & 160 & 320 \\
\hline Size of Typical Checkpoint & Bytes & $50.0 \mathrm{E}+9$ & $150.0 \mathrm{E}+9$ & $750.0 \mathrm{E}+9$ & $1.5 \mathrm{E}+12$ & $3.0 \mathrm{E}+12$ \\
\hline Total Size of Checkpoints & Bytes & $1.0 \mathrm{E}+12$ & $6.0 \mathrm{E}+12$ & $60.0 \mathrm{E}+12$ & $240.0 \mathrm{E}+12$ & $960.0 \mathrm{E}+12$ \\
\hline Mesh Type(s) & Type & Structured & Semi & Semi & Unstructured & Unstructured \\
\hline Number of Nodes in Mesh & Nodes & $1.0 \mathrm{E}+9$ & $3.0 \mathrm{E}+9$ & $10.0 \mathrm{E}+9$ & $30.0 \mathrm{E}+9$ & $100.0 \mathrm{E}+9$ \\
\hline $\begin{array}{l}\text { Number of Field Variables/ } \\
\text { Node }\end{array}$ & Vars & $7-100$ & $7-100$ & $7-100$ & $7-100$ & $7-100$ \\
\hline \# Flops/ Node/ Time Step & $\begin{array}{l}\text { Flops/node/ } \\
\text { time step }\end{array}$ & $400.0 \mathrm{E}+0$ & $600.0 \mathrm{E}+0$ & $800.0 \mathrm{E}+0$ & $1.0 \mathrm{E}+3$ & $1.2 \mathrm{E}+3$ \\
\hline \# Flops Per Computation & Flops/run & $8.0 \mathrm{E}+15$ & $72.0 \mathrm{E}+15$ & $640.0 \mathrm{E}+15$ & $4.8 \mathrm{E}+18$ & $38.4 \mathrm{E}+18$ \\
\hline
\end{tabular}




\begin{tabular}{|c|c|c|c|c|c|c|}
\hline $\begin{array}{l}\text { Real Time Per } \\
\text { Computation }\end{array}$ & Seconds & $32.0 \mathrm{E}+3$ & $24.0 \mathrm{E}+3$ & $80.0 \mathrm{E}+3$ & $200.0 \mathrm{E}+3$ & $600.0 \mathrm{E}+3$ \\
\hline $\begin{array}{l}\text { Time Dependent } \\
\text { Visualization (Number of } \\
\text { Time Steps) }\end{array}$ & Time steps & $5.0 \mathrm{E}+3$ & $10.0 \mathrm{E}+3$ & $20.0 \mathrm{E}+3$ & $40.0 \mathrm{E}+3$ & $80.0 \mathrm{E}+3$ \\
\hline Real-Time Animation & Minutes & 2.78 & 5.56 & 11.11 & 22.22 & 44.44 \\
\hline $\begin{array}{l}\text { Frequency Archival } \\
\text { Output is Examined }\end{array}$ & Frequency & 40 & 30 & 20 & 20 & 20 \\
\hline \multicolumn{7}{|l|}{ Highest-End Platform } \\
\hline $\begin{array}{l}\text { Peak Performance Per } \\
\text { Node }\end{array}$ & Flops & $500.0 \mathrm{E}+6$ & $1.0 \mathrm{E}+9$ & $2.0 \mathrm{E}+9$ & $4.0 \mathrm{E}+9$ & $8.0 \mathrm{E}+9$ \\
\hline Number of Nodes & Nodes & $500.0 \mathrm{E}+0$ & $3.0 \mathrm{E}+3$ & $4.0 \mathrm{E}+3$ & $6.0 \mathrm{E}+3$ & $8.0 \mathrm{E}+3$ \\
\hline Memory Per Node & Bytes & $512.0 \mathrm{E}+6$ & $1.0 \mathrm{E}+9$ & $1.5 \mathrm{E}+9$ & $3.0 \mathrm{E}+9$ & $4.0 \mathrm{E}+9$ \\
\hline Total System Performance & Flops & $250.0 \mathrm{E}+9$ & $3.0 \mathrm{E}+12$ & $8.0 \mathrm{E}+12$ & $24.0 \mathrm{E}+12$ & $64.0 \mathrm{E}+12$ \\
\hline $\begin{array}{l}\text { Total System RAM } \\
\text { Memory }\end{array}$ & Bytes & $256.0 \mathrm{E}+9$ & $3.0 \mathrm{E}+12$ & $6.0 \mathrm{E}+12$ & $18.0 \mathrm{E}+12$ & $32.0 \mathrm{E}+12$ \\
\hline Interconnect Speed & Bytes/second & $150.0 \mathrm{E}+6$ & $300.0 \mathrm{E}+6$ & $1.0 \mathrm{E}+9$ & $3.0 \mathrm{E}+9$ & $9.0 \mathrm{E}+9$ \\
\hline Interconnect Latency & Seconds & $10.0 \mathrm{E}-6$ & $5.0 \mathrm{E}-6$ & $2.0 \mathrm{E}-6$ & $1.0 \mathrm{E}-6$ & $500.0 \mathrm{E}-9$ \\
\hline $\begin{array}{l}\text { Local Disk Capacity Per } \\
\text { Node }\end{array}$ & Bytes/node & $9.0 \mathrm{E}+9$ & $20.0 \mathrm{E}+9$ & $30.0 \mathrm{E}+9$ & $40.0 \mathrm{E}+9$ & $60.0 \mathrm{E}+9$ \\
\hline $\begin{array}{l}\text { Local Disk Bandwidth Per } \\
\text { Node }\end{array}$ & $\begin{array}{l}\text { Bytes/second/ } \\
\text { node }\end{array}$ & $20.0 \mathrm{E}+6$ & $25.0 \mathrm{E}+6$ & $30.0 \mathrm{E}+6$ & $35.0 \mathrm{E}+6$ & $40.0 \mathrm{E}+6$ \\
\hline $\begin{array}{l}\text { Parallel File System I/O } \\
\text { Bandwidth (Aggregate) }\end{array}$ & Bytes/second & $3.0 \mathrm{E}+9$ & $22.5 \mathrm{E}+9$ & $36.0 \mathrm{E}+9$ & $63.0 \mathrm{E}+9$ & $96.0 \mathrm{E}+9$ \\
\hline $\begin{array}{l}\text { Parallel File System I/O } \\
\text { channels }\end{array}$ & Count & $150.0 \mathrm{E}+0$ & $900.0 \mathrm{E}+0$ & $1.2 \mathrm{E}+3$ & $1.8 \mathrm{E}+3$ & $2.4 \mathrm{E}+3$ \\
\hline $\begin{array}{l}\text { Parallel I/O Bandwidth to } \\
\text { HSM Tape (Aggregate) }\end{array}$ & Bytes/second & $300.0 \mathrm{E}+6$ & $2.3 \mathrm{E}+9$ & $3.6 \mathrm{E}+9$ & $6.3 \mathrm{E}+9$ & $9.6 \mathrm{E}+9$ \\
\hline $\begin{array}{l}\text { Parallel I/O HSM Tape } \\
\text { Channels }\end{array}$ & Count & $30.0 \mathrm{E}+0$ & $180.0 \mathrm{E}+0$ & $240.0 \mathrm{E}+0$ & $360.0 \mathrm{E}+0$ & $480.0 \mathrm{E}+0$ \\
\hline $\begin{array}{l}\text { External LAN Bandwidth } \\
\text { (Aggregate) }\end{array}$ & Bytes/second & $1.0 \mathrm{E}+9$ & $2.0 \mathrm{E}+9$ & $4.0 \mathrm{E}+9$ & $8.0 \mathrm{E}+9$ & $16.0 \mathrm{E}+9$ \\
\hline External LAN Channels & Count & 10 & 20 & 30 & 40 & 50 \\
\hline $\begin{array}{l}\text { Depth of Memory } \\
\text { Hierarchy }\end{array}$ & Levels & 4 & 4 & 5 & 5 & 6 \\
\hline $\begin{array}{l}\text { Rendering Performance of } \\
\text { General Node }\end{array}$ & $\begin{array}{l}\text { Polygons/ } \\
\text { second }\end{array}$ & $1.0 \mathrm{E}+6$ & $2.0 \mathrm{E}+6$ & $4.0 \mathrm{E}+6$ & $8.0 \mathrm{E}+6$ & $16.0 \mathrm{E}+6$ \\
\hline $\begin{array}{l}\text { Aggregate Rendering } \\
\text { Performance of Platform }\end{array}$ & $\begin{array}{l}\text { Polygons/ } \\
\text { second }\end{array}$ & $500.0 \mathrm{E}+6$ & $6.0 \mathrm{E}+9$ & $16.0 \mathrm{E}+9$ & $48.0 \mathrm{E}+9$ & $128.0 \mathrm{E}+9$ \\
\hline \multicolumn{7}{|l|}{ Data System and Storage } \\
\hline $\begin{array}{l}\text { Bandwidth to Primary } \\
\text { Platform (Aggregate) }\end{array}$ & Bytes/second & $6.0 \mathrm{E}+9$ & $45.0 \mathrm{E}+9$ & $72.0 \mathrm{E}+9$ & $126.0 \mathrm{E}+9$ & $192.0 \mathrm{E}+9$ \\
\hline $\begin{array}{l}\text { Interconnect Bandwidth } \\
\text { per channel }\end{array}$ & Bytes/second & $100.0 \mathrm{E}+6$ & $750.0 \mathrm{E}+6$ & $900.0 \mathrm{E}+6$ & $1.3 \mathrm{E}+9$ & $1.3 \mathrm{E}+9$ \\
\hline Number of I/O Channels & Count & 60 & 60 & 80 & 100 & 150 \\
\hline $\begin{array}{l}\text { Storage System Bandwidth } \\
\text { to WAN }\end{array}$ & Bytes/second & $1.00 \mathrm{E}+08$ & $2.00 \mathrm{E}+08$ & $4.00 \mathrm{E}+08$ & $8.00 \mathrm{E}+08$ & $1.60 \mathrm{E}+09$ \\
\hline $\begin{array}{l}\text { Storage System Bandwidth } \\
\text { to LAN }\end{array}$ & Bytes/second & $1.00 \mathrm{E}+09$ & $2.00 \mathrm{E}+09$ & $4.00 \mathrm{E}+09$ & $8.00 \mathrm{E}+09$ & $1.60 \mathrm{E}+10$ \\
\hline $\begin{array}{l}\text { Storage System Bandwidth } \\
\text { to Visualization Engine }\end{array}$ & Bytes/second & $4.0 \mathrm{E}+9$ & $29.7 \mathrm{E}+9$ & $47.5 \mathrm{E}+9$ & $83.2 \mathrm{E}+9$ & $126.7 \mathrm{E}+9$ \\
\hline $\begin{array}{l}\text { Number of I/O Channels to } \\
\text { Visualization Engine }\end{array}$ & Count & 39.6 & 39.6 & 52.8 & 66 & 99 \\
\hline $\begin{array}{l}\text { I/O Bandwidth of Working } \\
\text { Disk }\end{array}$ & Bytes/second & $3.00 \mathrm{E}+09$ & $6.00 \mathrm{E}+09$ & $1.20 \mathrm{E}+10$ & $2.40 \mathrm{E}+10$ & $4.80 \mathrm{E}+10$ \\
\hline $\begin{array}{l}\text { Aggregate Capacity of } \\
\text { Working Disk }\end{array}$ & Bytes & $2.6 \mathrm{E}+12$ & $30.0 \mathrm{E}+12$ & $60.0 \mathrm{E}+12$ & $180.0 \mathrm{E}+12$ & $320.0 \mathrm{E}+12$ \\
\hline $\begin{array}{l}\text { I/O Bandwidth to HSM } \\
\text { Buffers }\end{array}$ & Bytes/second & $600.0 \mathrm{E}+6$ & $4.5 \mathrm{E}+9$ & $7.2 \mathrm{E}+9$ & $12.6 \mathrm{E}+9$ & $19.2 \mathrm{E}+9$ \\
\hline
\end{tabular}




\begin{tabular}{|c|c|c|c|c|c|c|}
\hline $\begin{array}{l}\text { Capacity of HSM Disk } \\
\text { Buffers }\end{array}$ & Bytes & $256.0 \mathrm{E}+9$ & $3.0 \mathrm{E}+12$ & $6.0 \mathrm{E}+12$ & $18.0 \mathrm{E}+12$ & $32.0 \mathrm{E}+12$ \\
\hline $\begin{array}{l}\text { Storage System Parallel } \\
\text { I/O Bandwidth to Tape }\end{array}$ & Bytes/second & $300.0 \mathrm{E}+6$ & $2.3 \mathrm{E}+9$ & $3.6 \mathrm{E}+9$ & $6.3 \mathrm{E}+9$ & $9.6 \mathrm{E}+9$ \\
\hline Total Capacity of HSM & Bytes & $1.25 \mathrm{E}+14$ & $1.50 \mathrm{E}+15$ & $3.00 \mathrm{E}+15$ & $9.00 \mathrm{E}+15$ & $1.60 \mathrm{E}+16$ \\
\hline Number of Tape Drives & Count & 30 & 180 & 240 & 360 & 480 \\
\hline Tape Drive I/O Bandwidth & Bytes/second & $10.0 \mathrm{E}+6$ & $12.5 \mathrm{E}+6$ & $15.0 \mathrm{E}+6$ & $17.5 \mathrm{E}+6$ & $20.0 \mathrm{E}+6$ \\
\hline Single Tape Capacity & Bytes & $1.00 \mathrm{E}+11$ & $2.00 \mathrm{E}+11$ & $4.00 \mathrm{E}+11$ & $8.00 \mathrm{E}+11$ & $1.60 \mathrm{E}+12$ \\
\hline $\begin{array}{l}\text { Aggregate Number of } \\
\text { Directories }\end{array}$ & Directories & $1.00 \mathrm{E}+09$ & $1.00 \mathrm{E}+10$ & $2.00 \mathrm{E}+10$ & $4.00 \mathrm{E}+10$ & $8.00 \mathrm{E}+10$ \\
\hline Aggregate Number of Files & Files & $1.00 \mathrm{E}+13$ & $1.00 \mathrm{E}+14$ & $2.00 \mathrm{E}+14$ & $4.00 \mathrm{E}+14$ & $8.00 \mathrm{E}+14$ \\
\hline \multicolumn{7}{|l|}{ Database Support } \\
\hline $\begin{array}{l}\text { Database Performance } \\
\text { (Transactions per second) }\end{array}$ & $\begin{array}{l}\text { Transactions/ } \\
\text { second }\end{array}$ & & & & & \\
\hline Database I/O Performance & Bytes/second & & & & & \\
\hline \multicolumn{7}{|l|}{ Visualization and Graphics } \\
\hline $\begin{array}{l}\text { I/O Bandwidth to Primary } \\
\text { Platform }\end{array}$ & Bytes/seconds & $2.0 \mathrm{E}+9$ & $32.0 \mathrm{E}+9$ & $48.0 \mathrm{E}+9$ & $640.0 \mathrm{E}+9$ & $800.0 \mathrm{E}+9$ \\
\hline Number of Channels & Count & 20 & 40 & 60 & 80 & 100 \\
\hline I/O Bandwidth to LAN & Bytes/seconds & $500.0 \mathrm{E}+6$ & $8.0 \mathrm{E}+9$ & $12.0 \mathrm{E}+9$ & $160.0 \mathrm{E}+9$ & $200.0 \mathrm{E}+9$ \\
\hline Number of Channels & Count & 5 & 10 & 15 & 20 & 25 \\
\hline I/O Bandwidth to WAN & Bytes/seconds & $200.0 \mathrm{E}+6$ & $3.2 \mathrm{E}+9$ & $4.8 \mathrm{E}+9$ & $64.0 \mathrm{E}+9$ & $80.0 \mathrm{E}+9$ \\
\hline Number of Channels & Count & 2 & 4 & 6 & 8 & 10 \\
\hline I/O Bandwidth to HSM & Bytes/seconds & $1.0 \mathrm{E}+9$ & $16.0 \mathrm{E}+9$ & $24.0 \mathrm{E}+9$ & $320.0 \mathrm{E}+9$ & $400.0 \mathrm{E}+9$ \\
\hline Number of Channels & Count & 10 & 20 & 30 & 40 & 50 \\
\hline $\begin{array}{l}\text { I/O Bandwidth to Working } \\
\text { Disk }\end{array}$ & Bytes/seconds & $1.0 \mathrm{E}+9$ & $2.0 \mathrm{E}+9$ & $4.0 \mathrm{E}+9$ & $8.0 \mathrm{E}+9$ & $16.0 \mathrm{E}+9$ \\
\hline 2D Display Resolution & Pixels^2 & $2.4 \mathrm{E}+6$ & $6.0 \mathrm{E}+6$ & $12.0 \mathrm{E}+6$ & $24.0 \mathrm{E}+6$ & $48.0 \mathrm{E}+6$ \\
\hline 2D Display Update Rate & Fields/second & $120.0 \mathrm{E}+0$ & $120.0 \mathrm{E}+0$ & $120.0 \mathrm{E}+0$ & $160.0 \mathrm{E}+0$ & $160.0 \mathrm{E}+0$ \\
\hline 3D Display Resolution & Pixels^2 & $3.6 \mathrm{E}+6$ & $13.5 \mathrm{E}+6$ & $36.0 \mathrm{E}+6$ & $90.0 \mathrm{E}+6$ & $216.0 \mathrm{E}+6$ \\
\hline 3D Display Update Rate & Fields/second & $60.0 \mathrm{E}+0$ & $80.0 \mathrm{E}+0$ & $80.0 \mathrm{E}+0$ & $80.0 \mathrm{E}+0$ & $80.0 \mathrm{E}+0$ \\
\hline $\begin{array}{l}\text { Degree of Immersion } \\
\text { Supported (Field Of View) }\end{array}$ & Degrees & $180.0 \mathrm{E}+0$ & $230.0 \mathrm{E}+0$ & $270.0 \mathrm{E}+0$ & $270.0 \mathrm{E}+0$ & $300.0 \mathrm{E}+0$ \\
\hline Number of Screens & Count & 2 & 3 & 4 & 5 & 6 \\
\hline $\begin{array}{l}\text { Number of Hardware } \\
\text { Pipes }\end{array}$ & Count & 8 & 12 & 16 & 32 & 64 \\
\hline $\begin{array}{l}\text { Rendering Performance } \\
\text { (shaded } 100 \text { pixels) }\end{array}$ & $\begin{array}{l}\text { Polygons/ } \\
\text { second }\end{array}$ & $80.0 \mathrm{E}+6$ & $180.0 \mathrm{E}+6$ & $320.0 \mathrm{E}+6$ & $960.0 \mathrm{E}+6$ & $1.3 \mathrm{E}+9$ \\
\hline Performance Per Pipeline & $\begin{array}{l}\text { Polygons/ } \\
\text { second }\end{array}$ & $10.0 \mathrm{E}+6$ & $15.0 \mathrm{E}+6$ & $20.0 \mathrm{E}+6$ & $30.0 \mathrm{E}+6$ & $20.0 \mathrm{E}+6$ \\
\hline Texture Fill Rate & Bytes/second & $70.0 \mathrm{E}+9$ & $144.0 \mathrm{E}+9$ & $230.0 \mathrm{E}+9$ & $600.0 \mathrm{E}+9$ & $1.2 \mathrm{E}+12$ \\
\hline Geometry Performance & $\begin{array}{l}\text { T-mesh } \\
\text { trans/second }\end{array}$ & $480.0 \mathrm{E}+6$ & $10.8 \mathrm{E}+9$ & $19.2 \mathrm{E}+9$ & $57.6 \mathrm{E}+9$ & $76.8 \mathrm{E}+9$ \\
\hline \multicolumn{7}{|l|}{$\begin{array}{l}\text { Volume Rendering } \\
\text { Performance }\end{array}$} \\
\hline 256^3 Dataset & Seconds & $50.0 \mathrm{E}-3$ & $25.0 \mathrm{E}-3$ & $15.0 \mathrm{E}-3$ & $8.0 \mathrm{E}-3$ & $4.0 \mathrm{E}-3$ \\
\hline 512^3 Dataset & Seconds & $200.0 \mathrm{E}-3$ & $100.0 \mathrm{E}-3$ & $50.0 \mathrm{E}-3$ & $25.0 \mathrm{E}-3$ & $10.0 \mathrm{E}-3$ \\
\hline 1024^3 Dataset & Seconds & $800.0 \mathrm{E}-3$ & $400.0 \mathrm{E}-3$ & $200.0 \mathrm{E}-3$ & $100.0 \mathrm{E}-3$ & $50.0 \mathrm{E}-3$ \\
\hline \multicolumn{7}{|l|}{$\begin{array}{l}\text { Isosurface Rendering } \\
\text { Performance }\end{array}$} \\
\hline 256^3 Dataset & Seconds & $10.0 \mathrm{E}-3$ & $6.0 \mathrm{E}-3$ & $4.0 \mathrm{E}-3$ & $3.0 \mathrm{E}-3$ & $2.0 \mathrm{E}-3$ \\
\hline 512^3 Dataset & Seconds & $40.0 \mathrm{E}-3$ & $30.0 \mathrm{E}-3$ & $20.0 \mathrm{E}-3$ & $10.0 \mathrm{E}-3$ & $40.0 \mathrm{E}-3$ \\
\hline 1024^3 Dataset & Seconds & $160.0 \mathrm{E}-3$ & $100.0 \mathrm{E}-3$ & $50.0 \mathrm{E}-3$ & $25.0 \mathrm{E}-3$ & $10.0 \mathrm{E}-3$ \\
\hline \multicolumn{7}{|l|}{ 3D Dataset Comparison } \\
\hline $256^{\wedge} 3$ Dataset & Seconds & $200.0 \mathrm{E}-3$ & $100.0 \mathrm{E}-3$ & $45.0 \mathrm{E}-3$ & $32.0 \mathrm{E}-3$ & $16.0 \mathrm{E}-3$ \\
\hline 512^3 Dataset & Seconds & $800.0 \mathrm{E}-3$ & $400.0 \mathrm{E}-3$ & $200.0 \mathrm{E}-3$ & $100.0 \mathrm{E}-3$ & $40.0 \mathrm{E}-3$ \\
\hline 1024^3 Dataset & Seconds & $3.2 \mathrm{E}+0$ & $1.6 \mathrm{E}+0$ & $800.0 \mathrm{E}-3$ & $400.0 \mathrm{E}-3$ & $200.0 \mathrm{E}-3$ \\
\hline
\end{tabular}




\begin{tabular}{|c|c|c|c|c|c|c|}
\hline \multicolumn{7}{|l|}{ Networking Technology } \\
\hline LAN Hardware Type & Type & HIPPI & HIPPI-64 & HIPPI-64 & WDM? & WDM? \\
\hline $\begin{array}{l}\text { LAN Hardware Bandwidth } \\
\text { Per Interface }\end{array}$ & Bytes/second & $1.00 \mathrm{E}+08$ & $8.00 \mathrm{E}+08$ & $8.00 \mathrm{E}+08$ & $8.00 \mathrm{E}+09$ & $8.00 \mathrm{E}+09$ \\
\hline Degree of LAN Parallelism & Count & 50 & 100 & 150 & 200 & 400 \\
\hline $\begin{array}{l}\text { WAN Hardware } \\
\text { Bandwidth (Aggregate) }\end{array}$ & Bits/second & $1.00 \mathrm{E}+09$ & $1.00 \mathrm{E}+10$ & $4.00 \mathrm{E}+10$ & $1.60 \mathrm{E}+11$ & $3.20 \mathrm{E}+11$ \\
\hline WAN Hardware Type & Type & ATM & ATM & WDM & WDM? & WDM? \\
\hline $\begin{array}{l}\text { Degree of WAN } \\
\text { Parallelism }\end{array}$ & Count & 1 & 4 & 8 & 16 & 32 \\
\hline LL LAN Bandwidth & Bytes/second & $5.00 \mathrm{E}+09$ & $8.00 \mathrm{E}+10$ & $1.20 \mathrm{E}+11$ & $1.60 \mathrm{E}+12$ & $3.20 \mathrm{E}+12$ \\
\hline $\begin{array}{l}\text { MPI-2 LAN Bandwidth } \\
\text { (Per Channel) }\end{array}$ & Bytes/second & $7.00 \mathrm{E}+07$ & $5.60 \mathrm{E}+08$ & $5.60 \mathrm{E}+08$ & $5.60 \mathrm{E}+09$ & $5.60 \mathrm{E}+09$ \\
\hline $\begin{array}{l}\text { MPI-IO LAN Transfer } \\
\text { Bandwidth }\end{array}$ & Bytes/second & $3.50 \mathrm{E}+09$ & $5.60 \mathrm{E}+10$ & $8.40 \mathrm{E}+10$ & $1.12 \mathrm{E}+12$ & $2.24 \mathrm{E}+12$ \\
\hline $\begin{array}{l}\text { TCP/IP LAN Bandwidth } \\
\text { (Aggregate) }\end{array}$ & Bytes/second & $4.00 \mathrm{E}+09$ & $6.40 \mathrm{E}+10$ & $9.60 \mathrm{E}+10$ & $1.28 \mathrm{E}+12$ & $2.56 \mathrm{E}+12$ \\
\hline $\begin{array}{l}\text { TCP/IP WAN Bandwidth } \\
\text { (Aggregate) }\end{array}$ & Bytes/second & $8.00 \mathrm{E}+08$ & $8.00 \mathrm{E}+09$ & $3.20 \mathrm{E}+10$ & $1.28 \mathrm{E}+11$ & $2.56 \mathrm{E}+11$ \\
\hline $\begin{array}{l}\text { Network Attached Disk } \\
\text { Bandwidth (Per Disk) }\end{array}$ & Bytes/second & $4.00 \mathrm{E}+07$ & $5.00 \mathrm{E}+07$ & $6.00 \mathrm{E}+07$ & $8.00 \mathrm{E}+07$ & $1.20 \mathrm{E}+08$ \\
\hline $\begin{array}{l}\text { Network Attached Tape } \\
\text { Bandwidth (Per Tape } \\
\text { Drive) }\end{array}$ & Bytes/second & $2.00 \mathrm{E}+07$ & $3.00 \mathrm{E}+07$ & $4.00 \mathrm{E}+07$ & $6.00 \mathrm{E}+07$ & $7.00 \mathrm{E}+07$ \\
\hline
\end{tabular}

\section{C.2.g. Networking Technology Road Map Rationale}

DVC/Distance Corridor Networking Technology will likely be driven by end-user requirements for highly effective collaborative sessions in advanced DVC theaters. Multiple streams of data (computed on the fly and stored), multidimensional graphics, video, audio, haptics (including tracking), and conventional information sources like CNN and faxes will all be shared over the National Optical Terabit Network connecting DVC sites. Subsets of the available technology will be accessible from the desktop or in mobile units, but the road map assumptions are for full DVC theater implementations. Unicast, multicast, reliable and unreliable streams of data will be sent among participants and National 100 TF computers, 100 PB archives, and 8 GPolygon-per-second ASCI-sized DVC engines. These streams will be mediated by local teraflop/terabyte/gigapolygon DVC theaters with $6 \mathrm{~K} \times 4 \mathrm{~K}$ stereocapable screens, 16-channel audio (with phase-arrayed speakers and beam-formed microphones), and dozens of cameras monitoring faces, gestures, and body/head positions. The DVC/Distance Corridor Networking Technology Road Map puts forth the score of major technologies that need acceleration.

The Networking Functionality and Technology Road Maps identify five major areas that may need R\&D investment to meet application requirements: availability of bandwidth, high-performance protocols, availability of network interface cards, QoS technologies, and network management and configuration. These areas have been chosen because they represent continuing challenges to the networking research and technology providers, and because they are rate-limiting in a variety of advanced application scenarios.

\section{Availability of Bandwidth}

We project that wide-area bandwidth will increase roughly at a rate indicated by Moore's Law, as driver electronics improve and as availability of fiber improves. Wide-area bandwidth is to first order limited by cost-not technology - and availability and driver opto-electronics and infrastructure dominate much of that cost. Wide-area commercial bandwidth availability and pricing is driven by aggregate traffic demands, which are currently (late 1998) dominated by largely voice traffic. This trend will change over the timeframe addressed with this report; by 2004, global networking is expected to be dominated by data traffic, though it will still be driven by aggregate demand rather than single application demand. Bandwidth estimates beyond OC-192 are based on the assumption that WDM (Wave Division Multiplexing) will be used to create multiple parallel channels in a single fiber, each running at OC-192, rather than increasing the performance of single channels, due to the high cost of electronics for higher channel speeds (N.B. DWDM is currently optimized for price at less than OC-192 per channel). 


\section{High-Performance Protocols}

A major challenge for the networking research community is to develop (or evolve current) protocols that are optimized for high-performance and support advanced QoS capabilities. Often performance bottlenecks are not due to poor protocol design per se (although some protocol layering can cause destructive interference in performance), but in poor implementation or configuration, or lack of appropriate integration with edge-system environments (i.e., operating systems). Research in this area is needed in: scalability of collective protocols (e.g., reliable multicast), operating system by-pass technology to improve edge device efficiencies and reduce latencies, parallel protocols that can bind multiple channels into single logical high-bandwidth channels, and tunneling and virtual network overlays to provide flexibility in network implementation.

\section{Availability of Network Interfaces}

We believe that one of the most critical problems facing the community is the availability of inexpensive highperformance Network Interface Cards (NICs). It is the lack of interfaces, rather than the lack of affordable wide-area bandwidth, that is limiting the development and exploitation of high-bandwidth capabilities. Key technology drivers are volume pricing and the availability of lasers and opto-electronics. It is unclear how the DOE/NSF community can significantly influence this problem.

\section{QoS Technologies}

Even with substantial improvement in bandwidth availability, demand is likely to exceed supply, thus creating a scarce resource situation. Quality of Service (QoS) or Differentiated Services (DiffServ) capabilities can then play an important role in appropriate resource allocation and management of these resources. QoS capabilities are needed for bandwidth management, providing a minimum of two service classes, and perhaps many more, providing the networking equivalent of express delivery, bulk delivery, and commodity service. QoS research also includes the development of resource brokers, negotiation protocols, user level APIs, advanced reservation schemes and traffic shaping and policing mechanisms. Finally, substantial work is needed in developing end-to-end QoS capabilities that include CPU scheduling, disk access and storage resource management, and graphics resources management.

\section{Network Configuration, Management and Performance Engineering}

Wide-area networks are intrinsically more complex than local-area networks, in part due to the additional technology that is needed for long distance transmission (e.g. routers, repeaters, amplifiers), but also due to the fact that wide-area network management is a cooperative distributed task conducted by many people from many locations. Wide-area networks also are more heterogeneous due to multiple carriers and technologies that must be interconnected. To better support advanced high-performance applications, research and development is needed to move us from manual ad-hoc techniques for network configuration and management to more automated and integrated environments. Work is also needed to develop and deploy more sophisticated and integrated measure and monitoring capabilities to enable end-to-end performance engineering to insure high performance to critical applications.

\section{C.2.h. Networking Requirements of Future High-End Scientific Simulation Applications}

\section{Introduction}

The DOE's Scientific Simulation Planning (SSP) initiative envisions radical changes in the techniques and technologies used to address complex scientific problems. In particular, the SSP proposes:

- A nearly three orders of magnitude increase in computational capabilities over 5 years (from today's 100 Gflop per second to 40 teraflops per second by 2004)

- A significant increase in the degree of interdisciplinary and inter-institutional collaboration in order to tackle challenging scientific problems, such as global change.

Both thrusts will require significant increases in network capabilities. In this document, we attempt to quantify these increases by analyzing the types of remote interaction that may occur in SSP projects, the network requirements of 
these interactions, and the frequency of these interactions. Our analysis is targeted towards the 2004 timeframe and is based on numerous assumptions regarding both technologies and usage modalities, which we attempt to document. We focus exclusively on SSP requirements and ignore other potentially important uses of DOE networks, such as high-energy physics data analysis. We do not consider international networking issues, which may in practice be important for several SSP science areas.

\section{Technology Assumptions}

We assume that SSP researchers will have access to two central compute engines offering 40 teraflop-per-second peak performance, with $30 \mathrm{~PB}$ of archival storage. I/O systems will provide $50 \mathrm{Gbps}$ to local disk and system area networks will provide $20 \mathrm{Gbps}$ to local archival storage. In addition, a number (4-6?) of additional sites will house smaller (2-10 teraflop-per-second) computers with appropriately scaled storage systems.

We also assume that the standard scientific desktop will provide a $2000 \times 2000$ pixel, 32-bit, 40 frames-per-second, stereo display. Advanced immersive display devices will provide 4000 x 4000 pixel, 32-bit, 4-wall (either in a CAVE or PowerWall configuration), 80 frames-per-second, stereo displays. These display technologies translate to $10 \mathrm{Gbps}$ and $325 \mathrm{Gbps}$, respectively, in the absence of any compression.

\section{SSP Network Usage Model: Modalities}

We define eight primary usage modalities for future networks:

- Real-time visualization

- Computational steering

- Interactive data exploration

- $\quad$ Remote $\mathrm{I} / \mathrm{O}$

- Data analysis

- Collaboration

- Remote instruments

- Metacomputing

We describe each of these below, and also provide justifications for their expected bandwidth requirements, for "low" (minimum acceptable performance for advanced applications), "moderate" (enhanced performance, still well within the realm of technological feasibility) and "high" (at the edge of the envelope) scenarios. These requirements are summarized in a table at the end of this section.

While our analysis focuses on bandwidth requirements, most applications will also require various advanced network services such as QoS guarantees, multicast, security, etc.

Real-time Visualization. The high simulation rates enabled by teraflop-per-second computers can permit interactive use of simulation codes. In this mode, a user runs an application on a remote supercomputer and sends, in real time, output data to a local display, rather than post processing it after the simulation is completed.

The communication requirements of remote visualization are bounded from above by the display rates of the user's display device and the rate at which data can be output by a simulation. As we saw above, display rates can be substantial: 10-325 Gbps. Output rates of future supercomputers are expected to be able to reach these levels, although network interfaces and protocols will require substantial improvements to deal with more than a few $10 \mathrm{~s}$ of Gbps.

Another bound on remote visualization data rates is provided by the bandwidth of the human visual system, which has been estimated at $1 \mathrm{Gbps}$. However, extremely sophisticated techniques (e.g., gaze-directed rendering) would be required to provide a completely visually realistic scene at this low (relative to the resolution of the human eye: 5000 x 5000 pixels x 60 frames-per-second $\mathrm{x} 32$-bits $=48 \mathrm{Tbps}$ ) data rate.

Another bound on remote visualization data rates is provided by the amount of "information" produced by a simulation, as we can in principle transfer that information to the user's display and visualize it there. For example, 
"real-time" (30 times per second) output can be obtained for a spectral atmospheric model on a 40 teraflop-persecond computer when running in "T85" configuration and dumping state every 6 simulated hours ${ }^{22}$. At this resolution, the model grid comprises $0.59 \mathrm{M}$ points, which, assuming some 10 values per point, translates into 47 MB of data per dump, or $11 \mathrm{Gbps}$ with 30 outputs per second. At any particular time, a user might be looking at a subset of all fields, or at some representation (e.g., isosurfaces) that does not depend on data values. A user might also accept lower temporal resolution. Hence, it seems reasonable that in this application, bandwidth requirements with local rendering might be around $1 \mathrm{Gbps}$. It is important to emphasize that other applications can have significantly higher data rates: in this climate modeling scenario, we output only once every approximately 50 time steps.

As this discussions indicates, there are numerous tradeoffs to be made between the spatial and temporal resolutions of the simulation and visualization, the fidelity of the visualization, the amount of local computation performed, etc. However, while various compression techniques can be used to reduce bandwidth requirements (to any arbitrarily small amount), the value of the teraflop-per-second computer is reduced correspondingly. Taking these factors into account, we estimate 0.5 Gbps as a "low" data rate, 2.0 Gbps for "moderate", and 20 Gbps for "high".

Computational steering. A natural enhancement to remote visualization is interactive control of the simulation, whether to set parameter values, guide mesh refinement, or whatever. This mode of use has two principal implications for networking infrastructure

- Remote visualization output becomes latency sensitive, as interactive control will presumably occur in response to this output.

- Additional, low-bandwidth but latency-sensitive control streams must be accommodated. Otherwise, data rates are the same as for real-time visualization.

Interactive data exploration. While remote visualization can be expected to become increasingly important on teraflop-per-second systems, it will still be common for application data to be computed in a batch-oriented fashion and then "explored" later, either via direct visualization or by applying analysis programs that generate derived data products.

The communication requirements associated with interactive data exploration are similar to those associated with remote visualization and computational steering, except that simulation rates need not impose a lower bound on bandwidth requirements. Because data is already computed, the only physical limits on communication rates (other than the capacity of the network) are the rate at which it can be transferred from storage at the remote site, and the rate at which the human visual system can absorb it. In consequence, it becomes less attractive to transmit encoded representations of the eventual visualization (such as the original data); it will often make more sense to transmit the visualization output directly. We scale data rates accordingly; see the table.

Remote I/O. The "interactive data exploration" modality assumes that data is stored at the central facility where it was computed. However, as data will often be accessed multiple times once generated, it may make sense to transfer the data to the site(s) where it will be consumed. In the limit, this transfer may be achieved by performing "remote output" to a remote storage system, with no data being stored at the central site at all. In some situations, this data may be multicast to multiple recipients; e.g., climate data may be transferred to multiple regional centers.

One upper bound on the amount of data that may be transferred in this way is the rate at which simulations of interest generate output. As noted above, a low-resolution climate model may output data at around $11 \mathrm{Gbps}$. The Accelerated Climate Prediction Initiative program plan suggests that 52 PB of data may be generated per year by higher resolution models, which corresponds to $1.6 \mathrm{Gbps}=13 \mathrm{Gbps}$. Presumably some filtering can be performed to reduce the amount of data transferred to remote sites, but it is also the case that regional climate studies require high temporal and spatial resolution data. Assuming that filtering reduces data requirements by $1 / 10^{\text {th }}$, we obtain a requirement for a $1 \mathrm{Gbps}$ data rate to each of 4-6 regional centers in the climate model case alone.

\footnotetext{
${ }^{22}$ Running at 5 GF (on a 16-processor C90), a T170 18-level model configuration can simulate one day in about 12 minutes. Halving the resolution to T85 reduces computational requirements by around six; assuming a sustained 5 teraflops-per-second and an output rate of four time per simulated day, we obtain $(4 * 6 * 1000) /(12 * 60)=33$ outputs/sec. The model grid comprises some $128 * 256 * 18=0.59 \mathrm{M}$ points.
} 
Data analysis. The preceding discussion emphasized interactive visualization of simulation output and exploration of remote datasets. Another important mode of use for SSP resources will be batch-mode data analysis; e.g., to locate datasets that contain "interesting" events, to compute statistical properties of simulation output, or to correlate experimental data and simulation results. Many of these applications will require large data transfers.

An upper bound on data rates associated with this application is the data rate of the system area network on a teraflop-per-second computer, which, as noted above, is expected to reach $20 \mathrm{Gbps}$ by 2004 . Another upper bound that will often apply is the data rate of the tertiary storage system, which we hope might reach 8 Gbps by 2004. (This figure is based on information in the DVC Workshop report.)

Collaboration. The preceding discussion has focused on activities performed by a single user. In practice, we anticipate that multiple users will perform many data visualization and analysis tasks cooperatively, and that these users will frequently be located at different sites. Advanced collaboration technologies will be used to enhance the ability of these users to exchange information.

Collaboration increases network requirements both by increasing the number of locations to which data must be delivered, and by introducing new types of data traffic, for such purposes as tracking, video, and audio. See "TeleImmersion Data Flow Types" table in Section C.2.d. Tele-Immersion Networking Requirements for a summary of some of the flows that may be encountered, along with estimated network performance characteristics.

Remote instruments. While scientific instrumentation is not a major SSP focus, future networks will need to support remote operation of scientific instruments. Networking requirements range from high-resolution video, audio, and control for remote operation to real-time data transfer for remote data analysis. Bandwidth requirements for realtime data transfer vary tremendously according to the instrument involved. For current Advanced Photon Source beamline detectors, $80 \mathrm{Mbps}$ is an upper bound; improvements in read-out capabilities may increase this to $5 \mathrm{Gbps}$ in the next few years.

Metacomputing. In metacomputing, high-speed networks are used to couple multiple computers in order to enable the solution of problems too large to solve on a single system. Because individual supercomputers are themselves scarce and highly sought after resources, we can imagine that this mode of use will be relatively rare. But it can be effective, if either the number of computers that can be connected is large (e.g., 10 mid-sized supercomputers can be combined to provide the capabilities of one very large system) or if the problem at hand is very time critical (e.g., computing the outcome of a natural disaster).

We do not have enough experience with metacomputing applications to be able to place bounds on their networking requirements. In general, the larger the bandwidth, the more applications that can be supported. One aggressive upper bound is $1 / 10^{\text {th }}$ of the bisection bandwidth of an individual computer (for $40 \mathrm{TF} / \mathrm{s}$ technology we estimate this to be $10 \mathrm{Tbps}$ ). A less aggressive upper bound is obtained by assuming that smaller computers are to be connected (e.g., 5 teraflop-per-second machines with 1 Tbps bisection bandwidth) and requiring only $1 / 100^{\text {th }}$ of the bisection bandwidth: i.e., 10 Gbps.

\section{SSP Network Usage Model: Number of Users}

We assume that the "SSP community" will comprise approximately 2,000 full-time researchers at around 20 national laboratories (DOE, NSF, NASA, NOAA) and 100 universities. We assume that sites can be categorized as:

- Level 1 sites house high-end (40 teraflop-per-second) computers. There are perhaps two such sites.

- Level 2 sites house smaller (5 teraflop-per-second) computers, and substantial research communities. There are perhaps 5 such sites.

- Level 3 sites house substantial research efforts (e.g., NOAA labs or other DOE labs). There are perhaps 10 such sites.

- Level 4 sites house individual researchers and research groups at universities and other locations. There may be 100 such sites.

We assume that of the 2,000 SSP researchers, $10 \%$ (i.e., 200) will be using network resources during peak periods, whether to perform remote visualization, steer remote computations, analyze remote datasets, or collaborate with colleagues. We also assume that $80 \%$ of these users (160) will be operating in the "low" performance regime, while 
the other $20 \%$ (40) are operating in the "moderate" performance regime. The following table is an estimate of network requirements in this scenario, with the three right hand columns denoting number of "low" users, number of "moderate" users, and total bandwidth requirement for each usage modality. We term this scenario "moderate" because while it assumes a fairly large user community, it does not assume that any users operate at the "high" end of the performance spectrum. Also, we ignore metacomputing in this analysis; while this could add significantly to overall network bandwidth in certain situations, we are not convinced that it will be used often enough to warrant special consideration. Note the total bandwidth requirement of 170 Gbps.

\begin{tabular}{|c|c|c|c|c|c|c|}
\hline \multirow[b]{2}{*}{ Modality } & \multicolumn{3}{|c|}{ Bandwidth (Gbps) } & \multicolumn{3}{|c|}{ Moderate Scenario } \\
\hline & Low & Moderate & High & \#Low & \#Moderate & Total \\
\hline Real-Time Visualization & 0.5 & 2.0 & 20.0 & 10.0 & 4.0 & 13.0 \\
\hline Computational Steering & 0.5 & 2.0 & 20.0 & 10.0 & 4.0 & 13.0 \\
\hline Interactive Data Exploration & 1.0 & 5.0 & 50.0 & 20.0 & 4.0 & 40.0 \\
\hline Remote I/O & 1.0 & 5.0 & 50.0 & 20.0 & 2.0 & 30.0 \\
\hline Data Analysis & 0.1 & 10.0 & 50.0 & 35.0 & 4.0 & 43.5 \\
\hline Collaboration & 0.1 & 1.0 & 10.0 & 60.0 & 20.0 & 26.0 \\
\hline Online Instruments & 0.1 & 2.0 & 10.0 & 5.0 & 2.0 & 4.5 \\
\hline Metacomputing & 10.0 & 100.0 & 1000.0 & - & - & - \\
\hline Total & & & & 160.0 & 40.0 & 170.0 \\
\hline
\end{tabular}

A second question to address is where this traffic is directed. Our assumptions are documented in the next table where the "\% traffic" column indicates the percentage of total traffic that enters or exits a site at the specified tier. Note that the total traffic over a particular network segment might be greater than the values quoted here if several sites share a common backbone. 


\section{C.3. Remote Computing Road Map}

\section{C.3.a. Remote Computing Functionality and Technology Road Maps}

\begin{tabular}{|c|c|c|c|}
\hline \multicolumn{4}{|c|}{$\begin{array}{l}\text { Remote Computing Road Map } \\
\text { Functionality Timeline }\end{array}$} \\
\hline & 1999 & 2001 & 2004 \\
\hline $\begin{array}{l}\text { Monitoring and } \\
\text { Debugging }\end{array}$ & $\begin{array}{l}\text { Remote collection and display of } \\
\text { performance and debugging data }\end{array}$ & $\begin{array}{l}\text { Closed loop performance tuning. } \\
\text { Application level debugging of } \\
\text { distributed applications }\end{array}$ & Self-tuning applications. \\
\hline $\begin{array}{l}\text { Resource } \\
\text { Management }\end{array}$ & $\begin{array}{l}\text { Manual resource discovery, } \\
\text { uniform interface to local } \\
\text { processor resource management }\end{array}$ & $\begin{array}{l}\text { Support for heterogeneous } \\
\text { resource sets, advance reservation } \\
\text { and QoS across administrative } \\
\text { domains. Automatic discovery and } \\
\text { selection based on simple } \\
\text { performance metrics. }\end{array}$ & $\begin{array}{l}\text { Automatic resource discovery and } \\
\text { scheduling integrating policy and } \\
\text { complex performance metrics } \\
\text { (data locality, machine affinity, } \\
\text { etc.) with dynamic rescheduling }\end{array}$ \\
\hline $\begin{array}{l}\text { Accounting and } \\
\text { Local Allocation } \\
\text { Policy }\end{array}$ & $\begin{array}{l}\text { Uniform access to sites with } \\
\text { established allocations }\end{array}$ & $\begin{array}{l}\text { Allocation "fungibility" between } \\
\text { cooperating organizations }\end{array}$ & $\begin{array}{l}\text { Free market policies based on } \\
\text { politically allocated "funny } \\
\text { money" }\end{array}$ \\
\hline $\begin{array}{l}\text { Fault Detection } \\
\text { and Response }\end{array}$ & Application specific fault response & $\begin{array}{l}\text { Reusable fault recovery strategies } \\
\text { and methods }\end{array}$ & $\begin{array}{l}\text { Consistent performance across } \\
\text { faults and resource degradation }\end{array}$ \\
\hline $\begin{array}{l}\text { Information, } \\
\text { Negotiation and } \\
\text { Dynamic Control }\end{array}$ & $\begin{array}{l}\text { Application-specific steering tools, } \\
\text { limited online reallocation based } \\
\text { on computational requirements }\end{array}$ & $\begin{array}{l}\text { Generic steering tools, integration } \\
\text { of QoS reservation and contract } \\
\text { violation into steering } \\
\text { infrastructure }\end{array}$ & $\begin{array}{l}\text { Constrained dynamic resource and } \\
\text { algorithm selection based on data } \\
\text { characteristics, user expectations } \\
\text { and resource availability }\end{array}$ \\
\hline Communication & $\begin{array}{l}\text { Efficient communication across } \\
\text { collections of heterogeneous } \\
\text { resource }\end{array}$ & $\begin{array}{l}\text { Support for complex dynamic } \\
\text { networked environments with } \\
\text { time-varying performance }\end{array}$ & $\begin{array}{l}\text { Application driven communication } \\
\text { optimization }\end{array}$ \\
\hline Security & $\begin{array}{l}\text { Single sign-on, applications } \\
\text { directed security, user-invoked } \\
\text { encryption and decryption services }\end{array}$ & $\begin{array}{l}\text { Policy based access control, } \\
\text { general delegation methods, group } \\
\text { based authentication protocols }\end{array}$ & $\begin{array}{l}\text { Secure collaborative environments } \\
\text { (general group security). } \\
\text { Automatic mapping of application } \\
\text { and site level policy into } \\
\text { underlying network and system } \\
\text { security mechanism (i.e., link level } \\
\text { encryption, etc). }\end{array}$ \\
\hline
\end{tabular}

\begin{tabular}{|c|c|c|c|}
\hline \multicolumn{4}{|c|}{$\begin{array}{l}\text { Remote Computing Road Map } \\
\text { Technology Timeline }\end{array}$} \\
\hline & 1999 & 2001 & 2004 \\
\hline $\begin{array}{l}\text { Monitoring and } \\
\text { Debugging }\end{array}$ & $\begin{array}{l}\text { Log-based tools, dynamic } \\
\text { instrumentation, remote debuggers, } \\
\text { performance visualization tools }\end{array}$ & $\begin{array}{l}\text { Performance assistants. } \\
\text { Correlation of distributed bugs. } \\
\text { Remote reduction and analysis of } \\
\text { performance and debugging data }\end{array}$ & $\begin{array}{l}\text { Adaptive application frameworks. } \\
\text { Integrated framework for } \\
\text { distributed collection, analysis and } \\
\text { notification of performance and } \\
\text { debugging information. } \\
\end{array}$ \\
\hline $\begin{array}{l}\text { Resource } \\
\text { Management }\end{array}$ & $\begin{array}{l}\text { Information infrastructure to } \\
\text { publish information about resource } \\
\text { capabilities, availability, etc., } \\
\text { standardized interfaces to local } \\
\text { resource management technologies }\end{array}$ & $\begin{array}{l}\text { QoS enabled networks, storage and } \\
\text { computational and visualization } \\
\text { resources. Reservation support in } \\
\text { local resource management } \\
\text { systems. End-to-end reservation } \\
\text { system. System and application } \\
\text { level resource discovery and } \\
\text { scheduling agents. }\end{array}$ & $\begin{array}{l}\text { Intelligent application and system } \\
\text { level scheduling agents } \\
\text { incorporating performance models } \\
\text { and simulation. }\end{array}$ \\
\hline $\begin{array}{l}\text { Accounting and } \\
\text { Local Allocation } \\
\text { Policy }\end{array}$ & $\begin{array}{l}\text { Remote access to local account } \\
\text { and allocation }\end{array}$ & $\begin{array}{l}\text { Allocation exchange methods with } \\
\text { fixed costing, integration of } \\
\text { support for network and storage } \\
\text { resources }\end{array}$ & $\begin{array}{l}\text { Incorporation of auction-based } \\
\text { methods into resource discovery } \\
\text { and allocation methods. }\end{array}$ \\
\hline $\begin{array}{l}\text { Fault Detection } \\
\text { and Response }\end{array}$ & $\begin{array}{l}\text { Fault detection and reporting } \\
\text { infrastructure. }\end{array}$ & Reusable fault handling libraries & $\begin{array}{l}\text { Agent-based fault monitoring and } \\
\text { recovery components }\end{array}$ \\
\hline
\end{tabular}




\begin{tabular}{|l|l|l|l|}
$\begin{array}{l}\text { Information, } \\
\text { Negotiation and } \\
\text { Dynamic Control }\end{array}$ & $\begin{array}{l}\text { Online information about resource } \\
\text { capabilities }\end{array}$ & $\begin{array}{l}\text { QoS and reservation of resources, } \\
\text { steering libraries and tools }\end{array}$ & $\begin{array}{l}\text { Methods for adaptive computation, } \\
\text { alternative algorithms, frameworks } \\
\text { for algorithm selection }\end{array}$ \\
\hline Communication & $\begin{array}{l}\text { Multi-protocol communication } \\
\text { with optimized default selections. } \\
\text { Support for reliable and unreliable } \\
\text { multicast. }\end{array}$ & $\begin{array}{l}\text { Dynamic method selection (i.e. } \\
\text { protocol, compression, encryption, } \\
\text { etc.) based on resource availability. } \\
\text { Parallel communication libraries } \\
\text { (network striping). Application- } \\
\text { specific techniques for latency } \\
\text { management. }\end{array}$ & $\begin{array}{l}\text { Extensible application specific } \\
\text { protocol composition and } \\
\text { automatic generation of optimized, } \\
\text { application specific protocol } \\
\text { stacks. Integration of performance } \\
\text { feedback into communication } \\
\text { algorithm selection. High- } \\
\text { performance reliable group } \\
\text { communication protocols }\end{array}$ \\
\hline Security & Common PK infrastructure & Integrated support for policy & $\begin{array}{l}\text { Group authentication and } \\
\text { encryption algorithms, VPN, } \\
\text { encryption hardware }\end{array}$ \\
\hline
\end{tabular}

\section{C.3.b. Remote Computing Road Map Rationale}

The Remote Computing Road Maps focus on the technologies required to support the distribution of DVC components across geographically distributed, separately administered resources. Remote computing technologies form a bridge between the abstractions seen by an application or end user and the services provided by the underlying infrastructure (i.e., networks and operating systems). Consequently, remote computing services are frequently referred to as middleware, and consist of services, APIs, and application-specific programming libraries.

The scopes of these road maps cover issues of remote access (sometimes called distance computing) as well as more traditional high-performance distributed computing environments, typically referred to as computational grids. We note that the distance computing problem is a sub-problem of the more general grid problem, and focus on this technology in the road maps, as the grid technology will be necessary to address issues of remote and distributed visualization in general.

These road maps consist of seven broad technology categories:

- Monitoring and debugging addresses the issues of extracting performance and debugging data from a large-scale distributed system and of using this information to tune the overall performance (i.e., speed, efficiency, etc.) of a running application.

- Resource management is essential for the discovery and selection of heterogeneous resource sets (e.g., processors, networks, storage). It encompasses a broad range of issues, including end-to-end application QoS requirements, and dynamic re-negotiation of application resource allocations.

- Accounting and local allocation policy is required to enable resource providers to effectively make their resources available for remote access via the grid middleware. This element of the road map is closely related to resource management.

- Fault detection and response will be critical in general grid environments - as the scale of the system and applications grows, the likelihood of faults will grow as well. We use the term "fault response" in place of "fault recovery" or "fault tolerance" to make explicit the fact that recovery may not be appropriate in certain situations.

- Information, negotiation, and dynamic control are issues central to the dynamic control of running applications; e.g., to change the resolution of a running simulation to achieve faster response, or to focus on some feature of interest in a sub-mesh of an active simulation. These features are typically referred to as computational steering, and are closely tied to resource management. Online modification of program behavior naturally makes the resource requirements of the application more dynamic.

- Communication - the grid infrastructure will be comprised of a heterogeneous set of networks. Effective use of underlying networking technologies and mapping of application requirements to available network services are critical for good application performance in distributed environments. Communication issues in remote computing range from dynamic protocol selection to construction of efficient application-specific protocol stacks.

- Security is a fundamental requirement for remote computing. Security in a computational grid is a unique problem since the environment will span separate administrative domains. In the security category we include the compete range of traditional distributed computing security issues. 
As general trend, we expect that these technologies will evolve to support so called adaptive applications and environments. These are applications that will interact with both the user and the underlying infrastructure to adjust their behavior, algorithms, and resource requirements to compensate for variations in resource availability and application requirements.

\section{C.4. Remote Visualization Road Map}

\section{C.4.a. Remote Visualization Functionality and Technology Road Maps}

\begin{tabular}{|c|c|c|c|}
\hline \multicolumn{4}{|c|}{$\begin{array}{l}\text { Remote Visualization Road Map } \\
\text { Functionality Timeline }\end{array}$} \\
\hline & \begin{tabular}{|r|}
1999 \\
\end{tabular} & 2001 & 2004 \\
\hline \multicolumn{4}{|c|}{ Remote Visualization } \\
\hline $\begin{array}{l}\text { Remote Graphics } \\
\text { Goal: Scalable, } \\
\text { adaptable, network- } \\
\text { aware graphics and } \\
\text { visualization tools }\end{array}$ & $\begin{array}{l}\text { Demonstrations of hybrid } \\
\text { rendering systems involving } \\
\text { remote and local graphics }\end{array}$ & $\begin{array}{l}\text { Demonstration of network-aware } \\
\text { graphics systems with appropriate } \\
\text { protocols and APIs }\end{array}$ & $\begin{array}{l}\text { Scalable, adaptive remote } \\
\text { visualization tools integrated into } \\
\text { networking infrastructure }\end{array}$ \\
\hline $\begin{array}{l}\text { Remote VR } \\
\text { Goal: Create } \\
\text { immersion (realistic, } \\
\text { stereo, head-tracked, } \\
\text { advanced sound, } \\
\text { haptic) with low lag }\end{array}$ & $\begin{array}{l}\text { Remote, single-user VR (head- } \\
\text { tracked, stereo, wide-FOV) based } \\
\text { on replicated, small datasets }\end{array}$ & & $\begin{array}{l}\text { Remote, multiple-user, low-lag VR } \\
\text { with large distributed datasets }\end{array}$ \\
\hline \multicolumn{4}{|l|}{ Shared Spaces } \\
\hline $\begin{array}{l}\text { Shared High } \\
\text { Resolution White } \\
\text { Boards }\end{array}$ & $\begin{array}{l}\text { Early versions of "white boards" } \\
\text { and "PowerWalls" designed for } \\
\text { presentations with almost no } \\
\text { interaction capabilities }\end{array}$ & $\begin{array}{l}\text { Large ( } 12 \text { ' by } 6 \text { '), high resolution } \\
\text { ( } 8 \mathrm{~K} \text { by } 4 \mathrm{~K}) \text { wall display with } \\
\text { natural input devices with } \\
\text { prototype software }\end{array}$ & $\begin{array}{l}\text { Distributed interactive } \\
\text { visualization applications tailored } \\
\text { to group tasks and meeting } \\
\text { environments }\end{array}$ \\
\hline $\begin{array}{l}\text { Immersive } \\
\text { Environments for } \\
\text { Telepresent } \\
\text { Meetings }^{24} \\
\text { Goal: Immersive, } \\
\text { high-resolution rooms } \\
\text { for multiple } \\
\text { participants, remote } \\
\text { (avatars) and local } \\
\text { (display) }\end{array}$ & $\begin{array}{l}\text { Desktop video conferencing } \\
\text { combined with embryonic VR } \\
\text { experiments }\end{array}$ & $\begin{array}{l}\text { Effective VR presence at meetings } \\
\text { from a fixed viewpoint }\end{array}$ & $\begin{array}{l}\text { Realistic depiction of remote } \\
\text { participants, multiple local } \\
\text { participants, and walk-around } \\
\text { capability }\end{array}$ \\
\hline $\begin{array}{l}\text { Semi-Immersive } \\
\text { Desktop for } \\
\text { Manipulation of } \\
\text { Mechanical Parts } \\
\text { Goal: Direct } \\
\text { taptic/visual } \\
\text { nanipulation of a virtual } \\
\text { rototype (acquired or } \\
\text { imulated) at a distance }\end{array}$ & $\begin{array}{l}\text { Stereo, head-tracked workstation } \\
\text { or table-top display technology }\end{array}$ & $\begin{array}{l}\text { Personalized high resolution, wide } \\
\text { FOV, stereo display with haptics } \\
\text { connected to remote simulation or } \\
\text { acquisition system }\end{array}$ & $\begin{array}{l}\text { Realistic remote inspection and/or } \\
\text { manipulation using your hand of } \\
\text { virtual or real prototypes }\end{array}$ \\
\hline
\end{tabular}

${ }^{23}$ Integration of many devices. Resolution over time.

${ }^{24}$ Unencumbered 


\begin{tabular}{|c|c|c|c|}
\hline \multicolumn{4}{|c|}{$\begin{array}{l}\text { Remote Visualization Road Map } \\
\text { Technology Timeline }\end{array}$} \\
\hline & \begin{tabular}{|r|}
1999 \\
\end{tabular} & 2001 & 2004 \\
\hline \multicolumn{4}{|c|}{ Network-Enabled Graphics Devices } \\
\hline $\begin{array}{l}\text { Multi-Graphics } \\
\text { Goal: Graphics systems } \\
\text { efficiently generating } \\
\text { and/or receiving } \\
\text { commands from } \\
\text { multiple applications } \\
\text { and sites }\end{array}$ & $\begin{array}{l}\text { Graphics subsystem accepting a } \\
\text { single command stream with } \\
\text { limited direct bandwidth to the } \\
\text { network }\end{array}$ & $\begin{array}{l}\text { Real-time guarantees from the } \\
\text { operating system and the network }\end{array}$ & $\begin{array}{l}\text { Graphics systems with fast context } \\
\text { switching capable of efficiently } \\
\text { generating/receiving streams } \\
\text { to/from multiple remote sites }\end{array}$ \\
\hline $\begin{array}{l}\text { Graphics and } \\
\text { Multimedia } \\
\text { Streams and } \\
\text { Protocols } \\
\\
\text { Goal: Distributed } \\
\text { synchronized, } \\
\text { prioritized, multi- } \\
\text { resolution media } \\
\text { streams (9 types) in an } \\
\text { immersive } \\
\text { environment }\end{array}$ & $\begin{array}{l}\text { Multicast versions (e.g. PIM) of } \\
\text { remote graphics protocols (e.g. } \\
\text { GLX) }\end{array}$ & $\begin{array}{l}\text { Enhance and standardize media } \\
\text { streams with graphics, audio, } \\
\text { video, and haptics; prioritize data } \\
\text { streams, multi-resolution data } \\
\text { streams }\end{array}$ & $\begin{array}{l}\text { Protocols for distributed } \\
\text { interacting media streams; } \\
\text { synchronized media streams in an } \\
\text { immersive environment }\end{array}$ \\
\hline Teleconferencing & Session management; archiving & & \\
\hline \multicolumn{4}{|l|}{ Remote Rendering } \\
\hline $\begin{array}{l}\text { Remote Rendering } \\
\text { via RGBA+Z } \\
\text { Image } \\
\text { Transmission } \\
\text { Goal: } 8 \mathrm{Kx} 4 \mathrm{~K} @ 60 \mathrm{~Hz}\end{array}$ & $\begin{array}{l}\text { Preliminary experiments over } \\
\text { local-area networks }\end{array}$ & $\begin{array}{l}\text { Integrate real-time compression/ } \\
\text { decompression technology with } \\
\text { graphics systems }\end{array}$ & $\begin{array}{l}\text { Remote display of } 8 \mathrm{~K} \text { x } 4 \mathrm{~K} \text { images } \\
\text { of complex models@60 Hz }\end{array}$ \\
\hline $\begin{array}{l}\text { Image Based } \\
\text { Rendering } \\
\text { Goal: Demonstrate } \\
\text { rendering of realistic } \\
\text { remote site using } \\
\text { image-based } \\
\text { rendering for } \\
\text { acquisition and } \\
\text { display }\end{array}$ & $\begin{array}{l}\text { Exploration of image-based } \\
\text { rendering representations and } \\
\text { algorithms }\end{array}$ & $\begin{array}{l}\text { Graphics systems that combine } \\
\text { traditional geometric techniques } \\
\text { with image-based rendering } \\
\text { techniques }\end{array}$ & $\begin{array}{l}\text { Demonstrate rendering of complex } \\
\text { environments or objects using } \\
\text { image-based rendering }\end{array}$ \\
\hline $\begin{array}{l}\text { Compression: } \\
\text { Geometry and } \\
\text { Textures } \\
\begin{array}{l}\text { Goal: Real-time 100:1 } \\
\text { compression of } \\
\text { graphics streams }\end{array} \\
\end{array}$ & $\begin{array}{l}\text { Experiments in texture and } \\
\text { geometry compression/ } \\
\text { decompression }\end{array}$ & $\begin{array}{l}\text { Context-dependent compression } \\
\text { for graphics primitives }\end{array}$ & $\begin{array}{l}\text { High-quality (up to) } 100: 1 \\
\text { compression of streaming graphics } \\
\text { primitives }\end{array}$ \\
\hline $\begin{array}{l}\text { Distributed } \\
\text { Rendering } \\
\text { Database } \\
\text { Management } \\
\text { Goal: Network } \\
\text { transparent } \\
\text { framework }\end{array}$ & $\begin{array}{l}\text { Adapt scene management APIs to } \\
\text { remote visualization }\end{array}$ & $\begin{array}{l}\text { Semi-automatically adapt } \\
\text { rendering styles and algorithms to } \\
\text { resources (compute, graphics, } \\
\text { network) available }\end{array}$ & $\begin{array}{l}\text { Network-transparent application } \\
\text { framework which automatically } \\
\text { adapts to resources }\end{array}$ \\
\hline \multicolumn{4}{|c|}{ Distributed Input and Interaction } \\
\hline $\begin{array}{l}\text { Distributed } \\
\text { sensing with } \\
\text { networked input } \\
\text { devices }\end{array}$ & $\begin{array}{l}\text { Network-enabled devices such as } \\
\text { cameras and possibly trackers }\end{array}$ & $\begin{array}{l}\text { Remote control of input and output } \\
\text { resources; untethered passive } \\
\text { tracking }\end{array}$ & $\begin{array}{l}\text { Sensor fusion for increased } \\
\text { accuracy, robustness, and } \\
\text { coverage; wide-area 3D tracking } \\
\text { and sensing of people }\end{array}$ \\
\hline
\end{tabular}




\begin{tabular}{|l|l|l|l|}
$\begin{array}{l}\text { Personal and } \\
\text { group networked } \\
\text { user interfaces }\end{array}$ & $\begin{array}{l}\text { Experiments with partitioned UI's } \\
\text { (3D rendering remote; GUI local) }\end{array}$ & $\begin{array}{l}\text { Interface toolkits for multiple local } \\
\text { and remote users; group floor } \\
\text { control }\end{array}$ & $\begin{array}{l}\text { Multi-system, multi-user, multi- } \\
\text { modal interactive techniques and } \\
\text { tools }\end{array}$ \\
$\begin{array}{l}\text { Goal: } \text { Multi-system, } \\
\text { multi-user, } \text { multimodal } \\
\text { UI }\end{array}$ & & & \\
\hline
\end{tabular}

\section{C.4.b. Remote Visualization Road Map Rationale}

\section{Introduction}

Successful deployment of remote visualization capabilities require a number of new or improved technologies to be in place. Many of these technologies are not unique to remote visualization, and their development will be driven by other imperatives. This section describes the most important of these remote visualization enabling technologies.

At a high level, these key technologies are concerned with specialized data compressed transport (of both pixel and geometric data), local caching of data, and remote user interfaces, including both the GUI software and the physical interface devices themselves. New specialized software interfaces by which applications will operate remotely must be carefully designed and standardized. Important capabilities that other technology focus areas must deliver include higher networking bandwidths, lower networking latency, more powerful visualization techniques, higher resolution display technology, and faster rendering technology, just to name a few.

Advancing the state of the art to these impressive new levels within the limited timeframe required will not be easy. Different forms of nurturing will be appropriate for different areas. In some cases, the technology is close to being ready for commercial productization, needing mostly good requirement guidelines. In other cases, additional university research is required. In yet others, standardization process and inter-company cooperation incentives are the most important next step.

\section{Functionality}

Remote visualization. Remote graphics is a subset of remote VR. Remote VR includes immersive technologies that perform head tracking and present wide Field-Of-View (FOV) imagery and require very low lag. Haptics and advanced sound systems are also considered in this category. We use the term "lag" to indicate the total time from the motion of the user's head to the arrival of new photons to the eyes. Desirable lag is roughly 1/60 of a second.

Network-aware means that the application adapts behavior (use of resource; e.g., dropping the sound channel or using a lower resolution) to the available resources provided by the network. The application is thus also tolerant to network variability.

Shared spaces. Shared spaces facilitate collaborative group activities and are much more useful when they can connect to other sites. Three types of spaces are described, each customized to a particular task or environment: a white board, an immersive office, and a workbench augmented with haptics. A real shared space could include all these capabilities and devices as well as support for other peripherals such as laptops and palmtops.

Video conferencing requires video display over the network at normal frame rates and quality levels.

\section{Technology}

\section{Network-enabled graphics}

Multi-graphics. Multi-graphics is a new term to indicate that a graphics system is able to generate and/or receive multiple streams of graphics commands simultaneously. It also requires efficient support for directly transporting graphics streams to and from the network. One solution to this problem is to provide multiple parallel graphics contexts and/or fast context switching or other real-time scheduling protocols in the graphics system. 
Graphics and multimedia streams and protocols. This row includes two tasks. The integration of 3D graphics protocols such as OpenGL with network protocols for multicasting and QoS. It also includes the development of standard protocols with embedded data streams to support common media data types, with associated priorities, levels of detail, and synchronization information. [The table "Tele-Immersion Data Flow Types" in Section C.2.d. Tele-Immersion Networking Requirements defines nine data types.]

\section{Teleconferencing.}

\section{Remote rendering}

Remote rendering via image transmission. Perhaps the most basic and obvious approach to remote visualization is to render images with a state-of-the-art, high-performance graphics rendering server and transmit the images using networking backbones and technology. Early experiments are promising but reveal a number of technological hurdles that must be overcome to reach our long-term goal of displaying $8 \mathrm{~K}$ x $4 \mathrm{~K} 8$-bit RGBA/Z images at $60 \mathrm{~Hz}$. Specifically real-time 20:1-100:1 compress/decompression techniques need to be developed since it is doubtful that the raw, brute force bandwidth of wide-area networks available in 2004 will have the necessary bandwidth. Research into latency tolerances and network loading is also necessary to handle various spectrum of interaction paradigms including: head-tracking, 3D mice, and delayed command request (asking for a display and waiting).

Image-based rendering. Image-based rendering is a new field of research that explores the boundaries of computer graphics and computer vision. Rendering can run the gamut from classical rendering of geometry (such as polygon rendering performed in graphics hardware) to interpolation methods, such as generating an image from a light-field. The boundary between pure image-based rendering techniques and rendering of geometric primitives is continuous and relatively unexplored. Further exploration of this field is required with huge potential for remote visualization. Prototypes of techniques based on combining geometry and image-based-rendering techniques will work with relatively simple geometries and a limited number of images (i.e. non-dense light fields).

The integration of image-based-rendering techniques with "standard" graphics-hardware-rendering techniques will begin to surface in prototype form. Investment in this research will have payoff for remote visualization as methods, which blend geometric and image-based rendering, are implemented in hardware, either through clever utilization of available hardware or realization of hardware accelerated image-based-rendering techniques. These combined techniques, which leverage network protocols, have the potential to impact remote visualization during this time frame. By replacing complex geometric models with image-based representations, a factor of 10-100:1 increase in complexity may be achievable.

Leveraging the compression/decompression technologies and the maturation of combining geometric with imagebased rendering systems, these systems will be capable of rendering complex environments. The use of multicamera rigs combined with image-based-rendering techniques can provide parts of the immersive environment for remote collaborative sessions.

Compression-geometry and textures. Compression of all graphics primitives (other than image compression of final rendered image)

- Textures - compression of all forms of texture maps: surface, shadow, environment, etc.

- Geometry - compression of all vertex data associated with triangles, vectors, dots; vertex data includes: position, normal, color (ambient, diffuse, specular, emissive), opacity, texture coordinates, material properties (specular power, etc.)

- Higher level geometry primitives: NURBS, subdivision surfaces, etc.

- Other scene-graph information: coordinate frames, spline motion paths, picking/collision bounds

Existing geometry compression techniques can achieve roughly $10 \mathrm{X}$ compression in data size over traditional representations. To achieve 100X compression, higher order compression techniques must be used, such as techniques that interpolate between geometric targets. These ideas need to be further developed.

Rather than compressing different graphics structures in isolation (image compress textures, geometry compress triangles), more optimized compression can be achieved by considering all elements of the scene-graph together. 
In many cases asymmetric compression/decompression times are acceptable (compression taking 100 times longer than decompression is okay if the compression can be precomputed as a batch pass, or if the data will be rendered many times before being updated). In other cases, "just-in-time" faster compression techniques will be required. Avoiding re-computation of connectivity information is extremely important to such techniques.

Geometry compression should not be applied blindly to the original surface data; simplification/retessellation techniques should be applied before or as part of the compression phase.

Distributed rendering database management. Another technique for distributing the graphics across a wide-area network is to distribute higher order data ranging from polygonal data to raw scientific and associated meta-data. This requires adaptive rendering data management and rendering data management protocols. Closely coupled to these protocols are compression and delta-encoding of the changes that may occur during an evolving calculation or during a shared collaborative session. The higher order nature of the data involved necessitates sophisticated network-wide resource management. The ultimate goal is application transparent remote rendering with automatic resource management, which has only been developed for very specialized cases and would need to be generalized for use in an ASCI environment.

\section{Distributed input and interaction}

Distributed sensing with networked input devices. More and more input and output devices will have digital interfaces. For example, cameras and microphones may be able to connect directly to the computer. The natural extension of this is to connect the input devices directly to the network, as is being done in home automation networks. The development of such devices will make it much easier to use their data streams.

As more and more input devices are deployed, new capabilities emerge. For example, multiple cameras may be used to cover a wider area. This requires the development of distributed sensor fusion protocols for interactive environments. A particularly important problem in this area is the unencumbered, tetherless tracking of people over wide areas. This is critical technology for VR applications. Finally, as more devices are used for input into distributed applications, issues arise as to how they are controlled and configured.

Networked personal and group interfaces. There are two issues: the development of user interface tools and interaction techniques involving multiple users, and the natural partitioning of user interfaces between local and remote machines. For example, the local machine may provide menus and other traditional user interface components, while 3D widgets and images are provided by remote machines.

\section{C.5. Remote Data Road Map}

\section{C.5.a. Remote Data Functionality and Technology Road Maps}

\begin{tabular}{|c|c|c|c|c|}
\hline \multicolumn{5}{|c|}{$\begin{array}{l}\text { Remote Data Road Map } \\
\text { Functionality Timeline }\end{array}$} \\
\hline & 1999 & 2001 & 2004 & $\begin{array}{c}2004 \\
\text { DECISION SUPPORT } \\
\end{array}$ \\
\hline $\begin{array}{l}\text { Remote } \\
\text { Access }^{25}\end{array}$ & FTP, HTTP, GASS & $\begin{array}{l}\text { User-controlled access to } \\
\text { distributed caches }\end{array}$ & $\begin{array}{l}\text { Transparent location } \\
\text { management }\end{array}$ & $\begin{array}{l}\text { Cache space must be } \\
\text { preemptively scheduled } \\
\text { and relevant data staged }\end{array}$ \\
\hline Data Fusion $^{26}$ & $\begin{array}{l}\text { Standard access methods } \\
\text { to different datasets }\end{array}$ & $\begin{array}{l}\text { Hierarchical catalogs that } \\
\text { integrate data from } \\
\text { different disciplines }\end{array}$ & Fusion of incomplete data & $\begin{array}{l}\text { Missing data supporting } \\
\text { the relevant simulations } \\
\text { must be identified and } \\
\text { generated }\end{array}$ \\
\hline $\begin{array}{l}\text { Interactive } \\
\text { Browsing }^{27}\end{array}$ & $\begin{array}{l}\text { On-the-fly filtering of } \\
\text { remote data, prefetching }\end{array}$ & $\begin{array}{l}\text { Use of hierarchical } \\
\text { encodings, more flexible } \\
\text { filtering operations }\end{array}$ & $\begin{array}{l}\text { Automated tracking of } \\
\text { user-specified interesting } \\
\text { features }\end{array}$ & $\begin{array}{l}\text { Find similar weather } \\
\text { events that have occurred } \\
\text { the area of interest }\end{array}$ \\
\hline
\end{tabular}

${ }^{25}$ Techniques for fetching a remote dataset

${ }^{26}$ Techniques for synthesizing new information from two or more remote sources

${ }^{27}$ Techniques for navigating through a remote dataset, with path taken determined by user (or program) control 


\begin{tabular}{|c|c|c|c|c|}
\hline $\begin{array}{l}\text { Ingest of Real- } \\
\text { Time Data }^{28}\end{array}$ & Manual & $\begin{array}{l}\text { Automatic real-time } \\
\text { cataloguing }\end{array}$ & Real-time self description & $\begin{array}{l}\text { Steerable satellite feeds } \\
\text { (new data sources) must } \\
\text { be directed at cataloguing } \\
\text { and cache manager }\end{array}$ \\
\hline $\begin{array}{l}\text { Persistence } \\
\text { Management }^{29} \\
\text { (Assured } \\
\text { Access) }\end{array}$ & Manual & $\begin{array}{l}\text { Semi-automated, user- } \\
\text { managed replication and } \\
\text { transactions }\end{array}$ & $\begin{array}{l}\text { Persistence without } \\
\text { replication }\end{array}$ & $\begin{array}{l}\text { Access to critical data } \\
\text { must be guaranteed, } \\
\text { regardless of the current } \\
\text { state of systems and } \\
\text { communications. }\end{array}$ \\
\hline $\begin{array}{l}\text { Dataset } \\
\text { Naming } \\
\text { (Obtaining } \\
\text { Dataset } \\
\text { Handles) } \\
\end{array}$ & $\begin{array}{l}\text { URL naming of remote } \\
\text { files }\end{array}$ & $\begin{array}{l}\text { Attribute-based naming of } \\
\text { remote files; e.g., MCAT }\end{array}$ & $\begin{array}{l}\text { Extensions to alternative } \\
\text { data sources, computed } \\
\text { data, etc. }\end{array}$ & $\begin{array}{l}\text { Locate data based on } \\
\text { incomplete specification; } \\
\text { tailor simulations to this } \\
\text { exercise, but have them } \\
\text { appear in data space }\end{array}$ \\
\hline File System $^{31}$ & $\begin{array}{l}\text { Inflexible, system-defined } \\
\text { distributed file system } \\
\text { structures }\end{array}$ & $\begin{array}{l}\text { User-defined virtual file } \\
\text { systems encompassing } \\
\text { remote files; parallel I/O } \\
\text { access methods }\end{array}$ & $\begin{array}{l}\text { User-directed, compiler- } \\
\text { driven file system access } \\
\text { strategies; remote access } \\
\text { to object-based file } \\
\text { systems }\end{array}$ & $\begin{array}{l}\text { "Here" is the space of data } \\
\text { that is of interest; } \\
\text { construct a browsable } \\
\text { view (file system) of the } \\
\text { namespace }\end{array}$ \\
\hline Access Control & $\begin{array}{l}\text { UNIX security and file } \\
\text { permissions }\end{array}$ & $\begin{array}{l}\text { Access control lists for } \\
\text { individual data elements } \\
\text { managed by distributed } \\
\text { stakeholders (file owner, } \\
\text { data policy makers) }\end{array}$ & $\begin{array}{l}\text { Access control is policy } \\
\text { based, trusted third parties } \\
\text { provide user attributes. } \\
\text { Access control preemption } \\
(!)^{33}\end{array}$ & $\begin{array}{l}\text { When an emergency } \\
\text { situation exists, it must be } \\
\text { possible to preempt } \\
\text { normal policy, and } \\
\text { provide unrestricted } \\
\text { access to all relevant data, } \\
\text { regardless of location } \\
\end{array}$ \\
\hline $\begin{array}{l}\text { Fidelity } \\
\text { Management }\end{array}$ & $\begin{array}{l}\text { Lossless and lossy } \\
\text { compression }\end{array}$ & $\begin{array}{l}\text { Hierarchical encodings, } \\
\text { multi-resolution } \\
\text { techniques }\end{array}$ & $\begin{array}{l}\text { Adaptive selection of } \\
\text { compression, encoding, } \\
\text { etc. }\end{array}$ & $\begin{array}{l}\text { Must be able to rapidly } \\
\text { scan data because it may } \\
\text { not, regardless of priority, } \\
\text { be able to access entire } \\
\text { datasets in timely fashion }\end{array}$ \\
\hline
\end{tabular}

\section{Remote Data Road Map Technology Timeline}

\begin{tabular}{|l|l|l|l|}
\hline & \multicolumn{1}{|c|}{$\mathbf{1 9 9 9}$} & \multicolumn{1}{|c|}{$\mathbf{2 0 0 1}$} & \multicolumn{1}{c|}{$\mathbf{2 0 0 4}$} \\
\hline $\begin{array}{l}\text { Data Access } \\
\text { Mechanisms }\end{array}$ & $\begin{array}{l}\text { User filters to generate subsets, } \\
\text { samples from sequential access }\end{array}$ & $\begin{array}{l}\text { Optimization of data layout in } \\
\text { tertiary storage for efficient access } \\
\text { to predefined subsets }\end{array}$ & $\begin{array}{l}\text { Optimization of data layout for } \\
\text { efficient access to post-defined } \\
\text { subsets (dynamic data } \\
\text { reorganization) }\end{array}$ \\
\hline $\begin{array}{l}\text { Catalogs and } \\
\text { Brokers }\end{array}$ & $\begin{array}{l}\text { Storage Resource Broker/MCAT } \\
\text { can retrieve datasets based on } \\
\text { characteristics }\end{array}$ & $\begin{array}{l}\text { Dataset federation through } \\
\text { standard distributed brokering } \\
\text { mechanisms; metadata translators } \\
\text { provide standard ways of mapping } \\
\text { between disciplines }\end{array}$ & $\begin{array}{l}\text { Active databases, supporting } \\
\text { dynamic computation of missing } \\
\text { data }\end{array}$ \\
\hline $\begin{array}{l}\text { Remote Access to } \\
\text { Deep Archives }\end{array}$ & $\begin{array}{l}\text { File system access parameters } \\
\text { provide only control mechanism }\end{array}$ & $\begin{array}{l}\text { Predefined filters and data access } \\
\text { mechanisms operating on remote } \\
\text { computer }\end{array}$ & $\begin{array}{l}\text { Uploadable user code controlling } \\
\text { data access and filtering; e.g., for } \\
\text { feature tracking }\end{array}$ \\
\hline Access Control & $\begin{array}{l}\text { Public key infrastructure for } \\
\text { identity authentication }\end{array}$ & $\begin{array}{l}\text { Distributed management of } \\
\text { authorization information supplied } \\
\text { by third parties }\end{array}$ & $\begin{array}{l}\text { General policy-based and state- } \\
\text { based access control, with ability } \\
\text { to change policies over time }\end{array}$ \\
\hline
\end{tabular}

${ }^{28}$ Techniques for ingesting, into a data catalog and deep archive, data from real-time sources such as programs or instruments.

${ }^{29}$ Techniques for managing the reliability of your data.

${ }^{30}$ E.g. sensor feeds into weather models may normally be cached and archived in only one place. At beginning of decision episode, critical sources are identified and automatic persistence management invoked.

${ }_{31}^{31}$ Extended versions of standard file system technologies that support distributed access.

${ }^{32}$ While each of these things is an issue even on local systems, there are distinct "remote" issues that need to be addressed; e.g., access strategies must deal with caching, striping, latency, security, etc.

${ }^{33}$ I.e., various stakeholders (users, security officers, etc.) can specify custom access policies; e.g., "only cleared personnel can access this file"

${ }^{34}$ These are primarily local issues (except insofar as all deep archive accesses are remote).

${ }^{35}$ E.g., a request for a regional climate dataset leads to (a) access to global data (b) run of regional model.

${ }^{36}$ The focus here is on software control, not archiving technologies themselves. 


\begin{tabular}{|l|l|l|l|}
$\begin{array}{l}\text { Location } \\
\text { Management }\end{array}$ & $\begin{array}{l}\text { Manual migration of data to } \\
\text { caches, tools for locating cached } \\
\text { copies }\end{array}$ & $\begin{array}{l}\text { Distributed data caching, } \\
\text { automatic management of } \\
\text { replication; QoS for performance } \\
\text { guarantes; e.g., on network, } \\
\text { prestaging }\end{array}$ & $\begin{array}{l}\text { Automatic migration via dynamic } \\
\text { monitoring; end-to-end QoS } \\
\text { incorporating archives and } \\
\text { integrated with job manager }\end{array}$ \\
\hline $\begin{array}{l}\text { Persistence } \\
\text { Management }\end{array}$ & $\begin{array}{l}\text { Manual replication at multiple } \\
\text { locations }\end{array}$ & $\begin{array}{l}\text { Error correcting code techniques, } \\
\text { manual creation and distribution of } \\
\text { replicas }\end{array}$ & $\begin{array}{l}\text { Automated error correction codes } \\
\text { and "block" distribution according } \\
\text { to required persistence }\end{array}$ \\
\hline $\begin{array}{l}\text { File System/ } \\
\text { Database }\end{array}$ & $\begin{array}{l}\text { UNIX type file-systems, metadata } \\
\text { catalogues, commercial DBMS }\end{array}$ & $\begin{array}{l}\text { Generalized secure remote } \\
\text { mounting of file system } \\
\text { components; parallel I/O } \\
\text { interfaces; serverless (cache-based) } \\
\text { file systems }\end{array}$ & $\begin{array}{l}\text { Data discovery and handling } \\
\text { integrated with file system; } \\
\text { integration of object persistence } \\
\text { with standard languages; query } \\
\text { optimization for distributed data }\end{array}$ \\
\hline
\end{tabular}

\section{C.5.b. Remote Data Road Map Rationale}

Terabyte-per-second computers will generate petabytes of data that will then be consumed by potentially large and geographically dispersed communities, who will want to:

- Access selected subsets for further analysis, perhaps generating derived datasets that must also be archived and subsequently accessible by the community.

- Compare simulated data with the results of other simulations or with experimental/observational data.

- Explore simulation datasets interactively to identify interesting features.

For example, the Accelerated Climate Prediction Initiative (ACPI) envisions teraflop-per-second computers performing 100 s of high-resolution climate simulations, generating $10 \mathrm{~s}$ of petabytes of data. This data will then be accessed by a community of perhaps 1,000 scientists at 10 core sites and 100 or more other institutions, some interested in analyzing the raw data, others in mining that data (e.g., looking for flood events), and others in derived quantities (e.g., Midwest air quality).

Effective use of petabyte datasets requires a remote data infrastructure that allows large remote datasets to be integrated into a scientist's problem solving process, without the scientists needing to understand a complex computing infrastructures. In particular, we require:

- Remote data access mechanisms that use replication and other location management techniques to ensure low-latency access to relevant information contained within large remote datasets.

- Data fusion techniques that allow analysis of data maintained at different locations and in different representations, and able to support analysis of incomplete datasets.

- Support for interactive browsing operations that allow users or programs to navigate through remote datasets to identify or follow features of interest, without requiring that the entire dataset be transferred.

- Techniques for the ingest of real-time data that allow data generated by simulations (or instruments) to be catalogued and incorporated into archives as it is generated.

- Persistence management mechanisms that allow users to control the life-time and reliability characteristics of their data; for example, by creating distributed replicas.

- Dataset naming techniques that allow uniform, attribute-based discovery, access, and (if data does not exist) generation of data regardless of physical location and storage format.

- File system techniques that support the creation of user-defined hierarchical and/or object-oriented views of data located across heterogeneous and geographically distributed infrastructures.

- Access control mechanisms that facilitate the sharing of data by allowing automatic control of access; for example, by supporting control on the basis of organizational affiliation, membership in scientific collaborations, etc.

- Fidelity control that allows both user-directed and automatic management of the information content of data transferred from remote archives; e.g., lossless and lossy compression, hierarchical and adaptive encodings.

\footnotetext{
${ }^{37}$ Distributed stakeholders can have joint management of access control lists

${ }^{38}$ The remote aspect of this is that physical separation is an aspect of all serious persistence management techniques
} 
The technologies required to provide this functionality will come in part from industry where, for example, distributed database and data mining technologies are being developed in support of large-scale decision support. However, the extremely large size of scientific datasets and the nature of the expected access patterns leads to unique requirements.

We list below primary technology challenges:

- Data organization and access mechanisms that allow high-speed access to a wide range of views of large scientific datasets. (This is a remote issue to the extent that (a) all accesses to deep archives are, in essence, remote, and (b) a large user community increases the range of accesses performed.)

- Catalogs and brokers for the discovery of data located in widely distributed archives on the basis of attribute descriptions rather than names. These techniques should support active databases, in which data values are computed when requested rather than retrieved from an archive.

- Mechanisms for orchestrating efficient remote access to deep archives via, for example, the uploading to an archive (or a distributed collection of cooperating archives) of specifications of required data, or even the code that will be used to identify and retrieve that data.

- Access control mechanisms that allow access to datasets to be managed on a per-element basis, according to policies established by multiple stakeholders (e.g., users, project managers, security officers) and also according to operations performed by the accessing user.

- Location management mechanisms that automate the process of creating distributed replicas of data, prestaging data to where it will be used, and so on, in order to eliminate/reduce latency associated with remote data access operations.

- Persistence management techniques that automate the process of ensuring reliability of access; e.g., by using replicas (or less bulky redundant encoding techniques) to ensure that vital datasets can be accessed across their life times, even if some archives are temporarily inaccessible.

- File system and database technologies that support efficient access to data maintained in multiple formats and at multiple locations, via standard interfaces. 